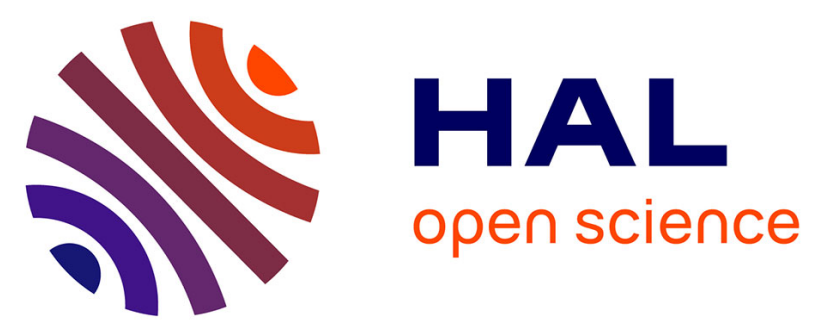

\title{
Cpe1786/IscR of Clostridium perfringens represses expression of genes involved in Fe-S cluster biogenesis.
}

Gaelle André, Elise Haudecoeur, Emmanuelle Courtois, Marc Monot, Bruno Dupuy, Dmitry A Rodionov, Isabelle Martin-Verstraete

\section{- To cite this version:}

Gaelle André, Elise Haudecoeur, Emmanuelle Courtois, Marc Monot, Bruno Dupuy, et al.. Cpe1786/IscR of Clostridium perfringens represses expression of genes involved in Fe-S cluster biogenesis.. Research in Microbiology, 2016, 10.1016/j.resmic.2016.03.002 . pasteur-01370878

\section{HAL Id: pasteur-01370878}

\section{https://hal-pasteur.archives-ouvertes.fr/pasteur-01370878}

Submitted on 23 Sep 2016

HAL is a multi-disciplinary open access archive for the deposit and dissemination of scientific research documents, whether they are published or not. The documents may come from teaching and research institutions in France or abroad, or from public or private research centers.
L'archive ouverte pluridisciplinaire HAL, est destinée au dépôt et à la diffusion de documents scientifiques de niveau recherche, publiés ou non, émanant des établissements d'enseignement et de recherche français ou étrangers, des laboratoires publics ou privés.

\section{(1) (1) $\$$}

Distributed under a Creative Commons Attribution - NonCommercial - NoDerivatives 44.0 
in Microbiology

Elsevier Editorial System(tm) for Research

Manuscript Draft

Manuscript Number:

Title: Cpe1786/IscR of Clostridium perfringens, represses expression of genes involved in Fes cluster biogenesis

Article Type: Special Issue Paper

Keywords: Rrf2 repressor; cysteine-dependent regulation; Fes clusters; clostridia; fermentation

Corresponding Author: Prof. Isabelle Martin-Verstraete, pHD

Corresponding Author's Institution: Institut Pasteur

First Author: Isabelle Martin-Verstraete, pHD

Order of Authors: Isabelle Martin-Verstraete, pHD; Gaelle André, pHD; Elise Haudecoeur, pHD; Emmanuelle Courtois, bachelor; Marc Monot, pHD; Bruno Dupuy, pHD; Dmitry Rodionov, pHD

Abstract: Cpe1786 of Clostridium perfringens is an Rrf2-type regulator containing the three-cysteine residues coordinating a Fe-S in IscR, the repressor controlling Fe-S homeostasis in enterobacteria. The cpe1786 gene formed an operon with iscSU involved in Fe-S biogenesis and tmrU. This operon was transcribed from a $\sigma A$-dependent promoter. We showed that in the heterologous host B. subtilis, Cpe1786 renamed IscRCp negatively controlled its own transcription. We constructed an iscR mutant in $\mathrm{C}$. perfringens. We then compared the expression profile of the strain 13 and of the iscR mutant. IscRCp controlled the expression of genes involved in Fe-S biogenesis, in amino-acid or sugar metabolisms, in fermentation pathways and in host compounds utilization. We then demonstrated using a ChIP-PCR experiment that IsCRCp interacted with its promoter region in vivo in C. perfringens and with the promoter of cpe2093 encoding an amino-acid ABC transporter. We utilized a comparative genomic approach to infer a candidate IscR-binding motif in clostridia and reconstruct IscR regulons in clostridia. We showed that point mutations in the conserved motif of 29 bp identified upstream of iscR decreased the cysteinedependent repression of iscR mediated by IscRCp. 


\section{Dear Editor,}

Please find enclosed a copy of an article entitled Cpe1786/IscR of Clostridium perfringens, represses expression of genes involved in $\mathrm{Fe}-\mathrm{S}$ cluster biogenesis. This paper described the characterization of IscR in the spore former pathogen, Clostridium perfringens. We combined studies in the heterologous host Bacillus subtilis, the inactivation of iscR in $C$. perfringens, a comparative transcriptome analysis of the wild-type strain and of the iscR mutant and a ChIPPCR experiment to study the role of IscR in C.perfringens. This is to our knowledge the first physiological characterization of an IscR regulator in Gram-positive bacteria.

This paper is a contribution to the Special Issue of Research in Microbiology on "Beneficial and detrimental spore-formers" edited by Véronique Broussole, Christina Nielsen-Leroux, Vincent Sanchis, Frédéric Carlin and Didier Lereclus.

We hope that this paper will be of sufficient importance and quality to be considered suitable for publication in Research in Microbiology.

Yours sincerely

Isabelle Martin-Verstraete 


\section{Cpe1786/lscR of Clostridium perfringens, represses expression of genes} involved in Fe-S cluster biogenesis

Gaelle André ${ }^{1,2}$, Elise Haudecoeur ${ }^{1,2}$, Emmanuelle Courtois ${ }^{1,2}, \operatorname{Marc}_{\operatorname{Monot}^{1}}$, Bruno Dupuy ${ }^{1}$, Dmitry A Rodionov ${ }^{3}$ and Isabelle Martin-Verstraete ${ }^{1,2^{*}}$

1. Institut Pasteur, Laboratoire de Pathogénèse des Bactéries Anaérobies, 28 rue du Docteur Roux, 75015 Paris, France.

10 2. Univ Paris 7-Denis Diderot, Sorbonne Paris Cité, 75205 Paris, France.

11 3.Institute for Information Transmission Problems, Russian Academy of Sciences, Moscow 12 127994, Russia.

13

14

15

Key words: Rrf2 repressor, cysteine-dependent regulation, Fe-S clusters, clostridia, fermentation 18

* corresponding author. mail: isabelle.martin-verstraete@pasteur.fr. Tel: 33 (1) 40613561 


\section{Abstract}

Cpe1786 of Clostridium perfringens is an Rrf2-type regulator containing the three-cysteine residues coordinating a $\mathrm{Fe}-\mathrm{S}$ in IscR, the repressor controlling $\mathrm{Fe}-\mathrm{S}$ homeostasis in enterobacteria. The cpe1786 gene formed an operon with iscSU involved in Fe-S biogenesis and tmrU. This operon was transcribed from a $\sigma^{\mathrm{A}}$-dependent promoter. We showed that in the heterologous host $B$. subtilis, Cpe1786 renamed IscR $_{C p}$ negatively controlled its own transcription. We constructed an iscR mutant in $C$. perfringens. We then compared the expression profile of the strain 13 and of the iscR mutant. IscR $\mathrm{R}_{\mathrm{Cp}}$ controlled the expression of genes involved in Fe-S biogenesis, in amino-acid or sugar metabolisms, in fermentation pathways and in host compound utilization. We then demonstrated using a ChIP-PCR experiment that $\mathrm{IscR}_{\mathrm{Cp}}$ interacted with its promoter region in vivo in $C$. perfringens and with the promoter of cpe2093 encoding an amino-acid ABC transporter. We utilized a comparative genomic approach to infer a candidate IscR-binding motif and reconstruct IscR regulons in clostridia. We showed that point mutations in the conserved motif of $29 \mathrm{bp}$ identified upstream of $i s c R$ decreased the cysteine-dependent repression of $i s c R$ mediated by $\operatorname{IscR}_{\mathrm{Cp}}$.

\section{Introduction}

Clostridium perfringens is a Gram-positive, spore forming anaerobic bacterium. Toxinotype A strains are the causative agent of food poisoning and gas gangrene. Numerous toxins and degradative enzymes secreted by this bacterium contribute to the pathogenicity of fatal infection like gas gangrene $[30,34]$. The synergistic actions of these toxins and enzymes on the host tissue are needed for the infection and a coordinated regulation of such virulence factors is observed. In C. perfringens strain 13, the VirS/VirR two-component system is involved in the global regulation of production of several toxins ( $\alpha-, \theta-, \kappa$-toxin) and of other virulence factors (capsular polysaccharide, sialidase, hyaluronidases or other enzymes able to degrade host compounds) [24, 35]. Genes involved in carbon, energy, base and amino acid metabolisms are also controlled by VirS/VirR [24, 35]. The response regulator VirR directly regulates the expression of $p f o A$ encoding the $\theta$-toxin and of three non-coding RNAs, the VR-RNA, VirU and VirT, which in turns control the expression of plc and colA encoding the $\alpha$ - and $\kappa$-toxin, respectively $[26,36]$.

Less is known about the physiology of $C$. perfringens. The $u b i G$ operon involved in methionine to cysteine conversion and in AI-2 production is controlled by VirS/VirR [25]. Several genes involved in sulfur metabolism are regulated in response to cysteine availability in $C$. perfringens 
strain 13 [1]. These genes are controlled by premature termination of transcription [10] through a cysteine specific T-box or a S-box dependent riboswitch. The $u b i G$ operon is submitted to a complex regulation [1]: i) an induction during cysteine starvation via a cysteine specific T-box present upstream of $u b i G$ that senses the level of charge of tRNA $\mathrm{A}_{\text {cys }}$; ii) a control by VirR through the VR-RNA and iii) a regulation by VirX, a regulatory RNA, which controls toxin production independently from VirR.

The expression of genes involved in Fe-S cluster biogenesis, in the maintenance of the cell redox and in the fermentation pathways is also induced during cysteine limitation via mechanisms different from the T-box and S-box systems [1]. Among the genes induced during cysteine limitation, there is cpe1786 encoding a regulator, which is a good candidate to participate in cysteine-dependent regulation in C. perfringens. Cpe1786 belongs to the widespread Rrf2 family of transcription factors. Notably, this family of regulators comprises: i) the Fe-S cluster biogenesis regulator, IscR [32]; ii) the NsrR repressor controlling the expression of NO detoxification systems [40]; iii) the global iron-responsive regulator RirA in Rhizobiaceae [15]; and iv) the global repressor of cysteine metabolism, CymR [7, 37]. Several mechanisms for the modulation of Rrf2-type regulator activity in response to environmental signals are involved. IscR, NsrR and RirA coordinate a Fe-S cluster via three conserved cysteines [8, 32, 40]. The Fe$\mathrm{S}$ cluster in IscR and NsrR contributes in sensing the pool of Fe-S or the presence of NO. These metal centers are sensitive to oxidation by NO or peroxide but also to iron availability [32]. Interestingly, the cysteine residues conserved other Rrf2-type regulators are absent in CymR, which displays a different mechanism of control of its activity with the formation of a complex with CysK, an $O$-acetyl-serine-thiol-lyase [39]. CysK via its substrate $O$-acetyl-serine, is the sensor of the cysteine pool and transmits this information to CymR.

In this work, we analyzed the regulatory role of the unique Rrf2-type regulator of C. perfringens, Cpe1786. 
Bacterial strains and culture conditions:

Escherichia coli strains were grown in LB medium and B. subtilis strains in SP or a sulfur-free minimal medium [7] containing either $1 \mathrm{mM}$ methionine or $1 \mathrm{mM}$ cystine. For the experiments involving expression of genes under the control of the xylA promoter, threonine $\left(50 \mathrm{mg} \mathrm{L}^{-1}\right)$ and $0.1 \%$ xylose were added. When needed, ampicillin $(100 \mu \mathrm{g} / \mathrm{ml})$ or chloramphenicol $(15 \mu \mathrm{g} / \mathrm{ml})$ was added to $E$. coli cultures while chloramphenicol $(5 \mu \mathrm{g} / \mathrm{ml})$ or spectinomycin $(60 \mu \mathrm{g} / \mathrm{ml})$ was added for B. subtilis cultures. C. perfringens strains were grown under anaerobic conditions $\left(10 \% \mathrm{H}_{2}, 10 \% \mathrm{CO}_{2}, 90 \% \mathrm{~N}_{2}\right)$ in TY $\left(30 \mathrm{~g} \mathrm{~L}^{-1}\right.$ bacto tryptone, $2 \mathrm{~g} \mathrm{~L}^{-1}$ yeast extract, $1 \mathrm{~g} \mathrm{~L}^{-1}$ thioglycolate, $\mathrm{pH} 7.4)$, BHI (37 $\left.\mathrm{g} \mathrm{L}^{-1}\right)$ or a sulfur-free minimal medium [1] containing either 1 $\mathrm{mM}$ cystine or $1 \mathrm{mM}$ homocysteine. When necessary, thiamphenicol $(5 \mu \mathrm{g} / \mathrm{ml})$ or erythromycin $(10 \mu \mathrm{g} / \mathrm{ml})$ was added to $C$. perfringens cultures.

\section{Strain and plasmid constructions}

The cpe 1786 promoter regions $(-131,+61$ or $-41,+61$ from the transcriptional start site) were amplified by PCR with the creation of EcoRI and BamHI sites. These DNA fragments were inserted between the EcoRI and BamHI sites of pAC6 [38] resulting in plasmids pDIA5820 and pDIA5837, respectively. These plasmids linearized by ScaI were used to transform the B. subtilis BSIP1798 or BSIP 2018 strains (Table 1).

Plasmid pDIA5820 was used to perform site directed mutagenesis with the Quikchange sitedirected mutagenesis Kit (Stratagene). Synthetic oligonucleotides complementary to opposite strands and containing different mutations (a $\mathrm{T} \rightarrow \mathrm{G}$ or $\mathrm{G} \rightarrow \mathrm{A}$ at position -22 or -19 , respectively) were used to amplify pDIA5820 (Table S1). The presence of the mutation was verified by sequencing. A plasmid containing the double mutation (T-22G and G-19A) was obtained by site directed mutagenesis using pDIA5840 (P(T-22G)cpe1786-lacZ) as template.

The complete coding sequence of cpe1786 $(+3$ to +503 from the transcriptional start site) was amplified by PCR. This fragment was inserted into pXT [21]. The resulting plasmid, pDIA5744,

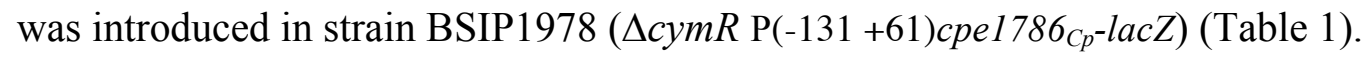

A DNA fragment corresponding to the cpe1786 gene (-131 to +497 from the transcriptional start site) fused to a sequence encoding the X-flag motif was amplified by PCR. This PCR product was inserted by TA cloning into the pGEM-Teasy vector (Promega, Madison, USA) to give pDIA5925. A $2.4 \mathrm{~kb}$ fragment corresponding to the pCB102 replicon and the catP marker of pMTL83151 (PmeI-AscI fragment treated by Klenow) [13] was cloned into the NaeI site of pDIA5925 giving pDIA5928. 
113 The ClosTron gene knockout system [12] was used to inactivate cpe1786. Primers IBS, EBS1d, 114 EBS2 to retarget the group II intron on pMTL007 to this gene (Table S1) were designed by the 115 Targetron design software (http://www.sigmaaldrich.com). We generated by overlap extension 116 PCR a 353 bp product that would facilitate intron retargeting to cpe1786. The PCR product was 117 cloned into pMTL007. The plasmid pMTL007-cpe1786-28a obtained was then introduced in $C$.

118 perfringens strain 13 by electroporation. Transformants were selected on BHI agar containing 119 thiamphenicol and then plated on BHI agar containing erythromycin. Chromosomal DNA of 120 clones resistant to erythromycin and sensitive to thiamphenicol was extracted using the kit 121 QIAamp DNA Mini Kit (Qiagen). PCR using the ErmRAM primers confirmed that ErmR phenotype was due to the splicing of the group I intron from the group II intron following integration. PCRs with primers IMV484 and IMV485 flanking the cpe1786 gene or with

124 IMV484 located in the cpe1786 gene (Table S1, Fig. S1) and EBSu were then performed to 125 verify the integration of the Ll.LtrB intron in cpe1786.

\section{Enzyme assays and volatile fatty acid analysis}

$127 \beta$-Galactosidase specific activity was measured as previously described [7]. Concentration of 128 proteins was determined by the method of Bradford. One unit of $\beta$-galactosidase is defined as the 129 amount of enzyme that produces $1 \mathrm{nmol} \mathrm{min}-1$ of $O$-nitrophenol (ONP) at $28^{\circ} \mathrm{C}$. The mean value 130 of at least three independent experiments was presented.

131 The end products of fermentation were detected in supernatants of strain 13 and the cpe1786 132 mutant after growth in minimal medium with $1 \mathrm{mM}$ cystine for $48 \mathrm{~h}$ at $37^{\circ} \mathrm{C}$ by gas-liquid 133 chromatography as previously described [2]. The amount of fatty acids was calculated by 134 comparison with an internal standard [6].

\section{RNA isolation, quantitative RT-PCR and 5'RACE analysis}

136 Total RNA from strain 13 and its derivative cpe1786 mutant grown in minimal medium with 137 cystine or homocysteine was extracted as previously described [1]. cDNAs were synthesized 138 with Superscript II Reverse Transcriptase (Invitrogen) using $1 \mu \mathrm{g}$ of RNA and 1pmol of hexamer 139 oligonucleotide primers (pDN6, Roche). Real-time quantitative PCR was performed with gene140 specific primers (Table S1) as previously described [1]. In each sample, the quantity of cDNAs 141 of a gene was normalized to the quantity of cDNAs of the gyrA gene. The relative change in 142 gene expression was recorded as the ratio of normalized target concentrations $(\Delta \Delta \mathrm{Ct})[16]$.

143 5'RACE assays were performed on total RNA extracted from strain 13 grown in minimal 144 medium in the presence of homocysteine using a 5'RACE System kit (Invitrogen). After reverse 145 transcription, the cDNAs were treated with Terminal deoxynucleotidyl transferase to add a 
146 polyC tail. PCR was then performed using a primer hybridizing with the polyC tail and gene-

147 specific primers (Table S1). PCR amplification products were sequenced.

148 DNA-array hybridization and microarray analysis.

149 The microarray analysis was performed using previously described Agilent microarrays (GEO

150 Database, GPL 9765) [1]. RNA was labeled with either Cy3 or Cy5 fluorescent dye (GE

151 healthcare) using the SuperScript Indirect cDNA labelling system kit (Invitrogen) according to

152 the manufacturer's recommendations. The cDNA synthesis, the hybridization, the washing and

153 the scanning were performed as previously described [1]. All the slides were analyzed using $\mathrm{R}$

154 and limma software (Linear Model for Microarray Data) from Bioconductor project

155 (www.bioconductor.org) and the normalization was performed as previously described [1]. The

156 complete experience dataset was deposited in the GEO database with accession numbers

157 GSE19359.

158 Chromatine immunoprecipitation of Cpe1786-XFlag bound to DNA

159 Strains CPIP01 (cpe1786) and CPIP11 (cpe1786 pDIA5927-cpe1786-XFlag) grown in minimal

160 medium containing $1 \mathrm{mM}$ cystine were incubated with $1 \%$ formaldehyde 10 minutes at $37^{\circ} \mathrm{C}$.

161 Cross-linking was quenched by addition of glycine $(125 \mathrm{mM})$. Cells were then collected by

162 centrifugation, washed twice with $20 \mathrm{mM}$ Tris- $\mathrm{HCl} \mathrm{pH7.5,} 150 \mathrm{mM} \mathrm{NaCl}$ and stored at $-80^{\circ} \mathrm{C}$.

163 Pellets were resuspended in $10 \mathrm{ml}$ of buffer A (50 mM Tris- $\mathrm{HCl}$ pH7.5, $150 \mathrm{mM} \mathrm{NaCl}, 1 \mathrm{mM}$

164 EDTA, 1\% Triton X-100, 0.1\% SDS) and sonicated in a water bath sonicator (Bioruptor,

165 Diagenode) to shear DNA to an average size of 300-500 bp. After removal of cells debris, the

166 supernatant was incubated in the presence of magnetic beads (Sigma) on a rotating wheel. The

167 magnetic beads were washed twice with buffer A, once with buffer A plus $500 \mathrm{mM} \mathrm{NaCl}$, once

168 with buffer B (10 mM Tris- $\mathrm{HCl} \mathrm{pH}$ 7.5, $1 \mathrm{mM}$ EDTA, 0.1\% Nonidet-P40) and once with 10

$169 \mathrm{mM}$ Tris-HCl pH 7.5, $1 \mathrm{mM}$ EDTA. Proteins were then eluted for $24 \mathrm{~h}$ at $37^{\circ} \mathrm{C}$ with $100 \mu \mathrm{l}$ of

170 elution buffer (50 mM Tris-HCl pH 7.5, 10 mM EDTA, 0.5\% SDS, $150 \mathrm{mM} \mathrm{NaCl,} \mathrm{Triton} \mathrm{X-100}$

$1710.5 \%$ ). Samples were treated $1 \mathrm{~h}$ at $56^{\circ} \mathrm{C}$ in $0.5 \mathrm{X}$ elution buffer containing $50 \mu \mathrm{g}$ of Proteinase $\mathrm{K}$.

172 DNA was purified using the QIAquick PCR purification Kit (QIAGEN). Chromatine

173 immunoprecipitation (ChIP) was analyzed by q-PCRs using primer pairs flanking the cpe1786,

174 cpe0664, cpe1031, cpe1371, cpe2093 and ldh promoter regions (Table S1). The reaction mixture

175 contained $1 \mu 1$ of DNA obtained by ChIP from strains CPIP11 or CPIP01, $400 \mathrm{nM}$ primers and

$17610 \mu \mathrm{l}$ of SYBR Green Mix (Roche) in a total volume of $20 \mu \mathrm{l}$. We used gyrA a gene not

177 regulated by Cpe1786 in transcriptome as a control. The ratio of enrichment by ChIP for a target

178 was calculated as follows: $2\left(\mathrm{Ct}_{\text {target }}-\mathrm{Ct}_{\text {gyrA }}\right)_{\mathrm{CPIP11}} /\left(\mathrm{Ct}_{\text {target }}-\mathrm{Ct}_{\mathrm{gyrA}}\right)_{\mathrm{CPIP} 01}$. The means of two 
independent experiments was obtained.

\section{Results}

\section{The Cpe1786 regulator of $C$. perfringens}

Cpe1786 of $C$. perfringens, a Rrf2-type regulator, shares $50 \%$ identity with the cysteine metabolism repressor CymR from B. subtilis [7] and $37 \%$ and $49 \%$ identity with the Fe-S cluster biogenesis regulator IscR from E. coli [33] and Thermincola potens [31], respectively. An alignment of CymR-type regulators, IscR-type regulators and Cpe1786 (Fig. S2) indicates that the three-cysteine residues coordinating the Fe-S cluster in IscR are conserved in Cpe1786 [8]. Three genes are located downstream of cpe1786. The cpe1785/iscS and cpe1784/iscU genes encode a cysteine desulfurase and a scaffold protein for $\mathrm{Fe}-\mathrm{S}$ assembly, respectively [3] while trmU (cpe1783) encodes an enzyme involved in thio-uridylation of tRNAs (Fig. S3A). The expression of these genes increased during cysteine starvation [1] suggesting that they can form an operon. RT-PCR experiments using primers hybridizing with cpe1786 and iscS, iscS and iscU or isc $U$ and $t m r U$ were performed and confirmed that these genes were cotranscribed (Fig. S1B). So, cpe1786 of $C$. perfringens forms an operon with an iscS-type gene and with $\operatorname{trm} U$ as found in B. subtilis [7] and with iscS and isc $U$ as observed in E. coli and in T. potens [31, 32] (Fig. S3A). We then characterized the cpe1786 promoter by determining its transcriptional start site by 5'RACE analysis. Transcription is initiated $39 \mathrm{bp}$ upstream of the translational start site. -10 (TATAAT) and -35 (TTGACA) boxes that perfectly match with the consensus for $\sigma^{\mathrm{A}}$-dependent promoters are found upstream of this transcriptional start site (Fig. 1).

\section{Cpe1786 controls cpe178 6transcription in the heterologous host $B$. subtilis}

To determine whether Cpe1786 controls its own transcription, we constructed a transcriptional fusion between the cpe1786 promoter region $(-131,+61)$ and $l a c Z$ and tested the effect of the addition of Cpe1786 on the expression of this fusion in the heterologous host B. subtilis. The fusion was integrated at the $a m y E$ locus of a $B$. subtilis $\triangle c y m R$ mutant or a $\triangle c y m R$ mutant containing at the $t h r C$ locus a copy of $\mathrm{P}_{x y l A}$-cpe1786. The resulting strains were grown in minimal medium in the presence of cystine or methionine corresponding to conditions of cysteine limitation [39]. The $\mathrm{P}(-131,+61)$ cpe1786-lacZ fusion was constitutively expressed in a B. subtilis cymR mutant. The introduction of Cpe1786 in this mutant led to a cysteine-dependent repression of this fusion (Table 2) as observed for cpe1786 expression in C.perfringens [1]. This result indicates that Cpe1786 represses its own transcription as observed for IscR in E. coli [33] 
and we renamed this regulator $\mathrm{IscR}_{\mathrm{Cp}}$. The expression of a second $\mathrm{P}(-41,+61)$ cpe1786-lacZ

213 fusion was also repressed in the presence of cysteine indicating that the DNA binding motif of

$214 \operatorname{IscR}_{\mathrm{Cp}}$ is located between position -41 and +61 from the transcriptional start site as classically

215 observed for repressors.

\section{Global regulation by the Cpe1786/IscR regulator in $C$. perfringens}

218 To study the role of $\mathrm{IscR}_{\mathrm{Cp}}$ in $C$. perfringens, we constructed a cpe1786/iscR mutant using the 219 Clostron system [12]. The group II intron was inserted into the iscR gene in antisense orientation immediately after the $28^{\text {th }}$ nucleotide in its coding sequence. To verify the insertion of the group II intron into iscR, PCRs were carried out using a primer internal of the target gene and the intron-specific primer EBSu or primers flanking the insertion site of the intron (Fig. S1C). To identify genes regulated by $\mathrm{IscR}_{\mathrm{Cp}}$ in $C$. perfringens, we further compared the expression profiles of strain 13 and the iscR mutant after growth in a minimal medium in the presence of cystine. 250 genes were differentially expressed in these two strains. We confirmed these transcriptome data by qRT-PCR analysis for several genes (Table 3). Some of the controlled genes including those with expression ratio above three-fold between these two strains, those associated with iron-sulfur clusters biogenesis, carbon or sulfur metabolism and the degradation of host compounds are presented in Table 3. Most of these genes (62\%) were derepressed in an iscR mutant as expected for the inactivation of a repressor. A large set of genes regulated by IscR $\mathrm{R}_{\mathrm{Cp}}$ $(50 \%)$ was also regulated in response to cysteine availability [1].

\section{Regulation of genes involved in iron-sulfur clusters biogenesis}

234 The expression of genes involved in Fe-S cluster biogenesis was up-regulated in the iscR mutant 235 (Table 3). IscR $\mathrm{Cp}_{\mathrm{p}}$ regulates its own transcription in response to cysteine availability in B. subtilis 236 (Table 2). Our transcriptome data also showed a 2-fold increase of iscS, isc $U$ and $\operatorname{trm} U$ 237 expression in the iscR mutant. This up-expression of genes located downstream from cpe1786/iscR might be due to the presence of a promoter in the group II intron or in the erm cassette and indicated the absence of a major polar effect of the iscR gene disruption on the expression of the downstream genes. The expression of cpe0664, encoding a 114 amino-acid protein belonging to the HesB family that probably corresponds to an A-type carrier required for

242 Fe-S biogenesis [41], increased in the iscR mutant (12.5-fold in transcriptome/27-fold in qRT243 PCR). This gene is also induced during cysteine starvation [1]. Isc $\mathrm{R}_{\mathrm{Cp}}$ controls iscS, isc $U$ and cpe0664 involved in $\mathrm{Fe}-\mathrm{S}$ clusters biogenesis likely in response to cysteine availability. 
The expression of cpe2092-cpe2093 and cpe1371 increased in the mutant in our transcriptome (Table 3). Cpe2092 and Cpe2093, which correspond to the ATP binding cassette and a solute binding protein fused to a permease of an $\mathrm{ABC}$ transporter, respectively, share $61 \%, 47 \%$ and $44 \%$ identity with YxeO, YxeN and YxeM from B. subtilis. The yxe operon, which is induced under conditions of cysteine limitation and belongs to the CymR regulon, is probably involved in the uptake and degradation of sulfur compounds including S-methyl-cysteine [5]. Cpe1371 shares similarity with symporters. The expression cpe1371 is also 5-fold derepressed during cysteine starvation [1] suggesting that Cpe1371 could also play a role in the uptake of sulfur compounds. So, IscR $\mathrm{R}_{\mathrm{Cp}}$ might regulate the uptake systems for sulfur-containing metabolites that might be required for the maintenance of pools of cysteine, the sulfur donor for Fe-S cluster biogenesis.

\section{Regulation of fermentation pathways}

The expression of $l d h$ encoding the lactate dehydrogenase increased 38 -fold in transcriptome and 130-fold in qRT-PCR in the iscR mutant compared to the strain 13 (Table 3 and Fig. 2A). By contrast, the expression of the cpe2297-cpe2301 operon, encoding the enzymes responsible for acetyl-CoA to butyryl-CoA conversion decreased in the mutant compared to strain 13 (0.1 to 0.3 -fold). These genes are also regulated in response to cysteine availability [1]. To confirm the role of $I_{s c R_{C p}}$ in the control of fermentation pathways, we analyzed the end products of fermentation of strain 13 and the iscR mutant grown $48 \mathrm{~h}$ in minimal medium containing cystine. The butyrate production decreased 2.5-fold in the iscR mutant (Fig. 2B). By contrast, lactate production drastically increased in the $i s c R$ mutant in agreement with the huge derepression of $l d h$ transcription in this mutant. So, the modulation of expression of key genes of fermentation pathways correlates with changes in the amount of lactate and butyrate produced.

\section{Regulation of genes involved in host compounds utilization}

NagL is a hyaluronidase ( $\mu$-toxins), which is probably involved in hyaluronic acid degradation, a host component. The nagL expression was induced in the $i s c R$ mutant (3.75 in transcriptome/ 8.8 in qRT-PCR) and during cysteine limitation [1] suggesting the involvement of IscR $_{\mathrm{Cp}}$ in its regulation in response to cysteine availability. The cpe0818 and cpe0866 genes were also more expressed in the iscR mutant (9.9- and 5.8-fold in transcriptome/16- and 15-fold in qRT-PCR) (Table 3). Cpe0866, which shares similarity with $\alpha$-N-acetyl-glucosaminidase, could also degrade host compounds. Finally, Cpe0818 encodes a protein similar to endo- $\beta-\mathrm{N}$-acetyl- 
278 glucosaminidases. These enzymes could be involved either in peptidoglycan hydrolysis such as

279 B. subtilis LytD protein or in the hydrolysis between two $\mathrm{N}$-acetyl-glucosamine residues of 280 glycoproteins. Two endo- $\beta$-N-acetyl-glucosaminidases that are active on (Man $)_{6}(\mathrm{GlcNAc})_{2} \mathrm{Asn}$ 281 and/or (Man $)_{5}(\mathrm{GlcNAc})_{2}$ Asn substrates exist in C. perfringens [14]. Cpe0818 probably degrades 282 glycoproteins to provide mannose and N-Acetyl-glucosamine to $C$. perfringens. Interestingly, an 283 operon encoding a PTS system (Cpe1463 to Cpe1466) belonging to the Mannose/Fructose 284 family of PTS and a gene encoding a phosphomannomutase (Cpe1873) were also up-regulated in 285 the iscR mutant. It is tempting to speculate that Cpe0818, the PTS system and the 286 phosphomannomutase are involved in host glycoprotein degradation and in the uptake and 287 utilization of the released sugars and that $\mathrm{IscR}_{\mathrm{Cp}}$ coordinately regulates the corresponding genes.

\section{Identification of IscR $R_{C p}$ direct targets in vivo by chromatine immunoprecipitation}

Among the large set of genes negatively controlled by IscR $_{C p}$ in transcriptome, we would like to identify some direct targets. For this purpose, we tested by ChIP the binding in vivo of IscR $\mathrm{R}_{\mathrm{Cp}}$ to a selection of controlled promoters identified in transcriptome. The IscR $\mathrm{R}_{\mathrm{Cp}}$ protein was modified by addition of a C-terminal 3XFlag-tag. The modified gene was expressed under the control of its own promoter. Strain CPIP11 (iscR pDIA5928-iscR-XFlag) and CPIP01 (iscR) used as a control were grown in minimal medium in the presence of cystine that corresponds to conditions of repression by $I_{s c R_{C p}}$. After in vivo cross-linking, DNA fragments bound to IscR $R_{C p}-X F l a g$ were enriched by immunoprecipitation using monoclonal antibodies raised against the XFlag. Immunoprecipitated DNAs were used as templates to amplify the promoter regions of 6 genes derepressed in the iscR mutant in transcriptome. We then performed q-PCR experiments and compared the relative quantity of DNA retained in strain CPIP11 compared to strain CPIP01 (iscR). The data were standardized using gyrA, a gene not regulated by $\mathrm{IscR}_{\mathrm{Cp}}$, as a control. After ChIP, we detected a $25+/-1$ and $4.5+/-1$ fold enrichment for the $i s c R$ and the cpe2093 promoter regions, respectively with strain CPIP11 compared to strain CPIP01. This clearly indicated that IscR $_{\mathrm{Cp}}$ controls its own transcription by binding to its promoter region and is a direct regulator of cpe2093-cpe2092 expression. By contrast, we observed an enrichment factor between 1 and 1.5 in ChIP experiments for the promoter regions of $l d h$, cpe0664, cpe1031 and cpe1371. For these genes, it is therefore difficult to discriminate between an absence of binding or a weak interaction of IscR $_{\mathrm{Cp}}$ to some of these promoters in our conditions.

\section{Identification of an IscR $\mathrm{C}_{\mathrm{Cp}}$ binding motif}


311 To identify a putative binding motif for IscR $\mathrm{R}_{\mathrm{Cp}}$, we first compared the promoter regions of iscR 312 and cpe2093. We identified a conserved sequence upstream of these two promoters (Fig. S3B).

313 In the iscR promoter region, the location of this motif (Fig. 1) is in agreement with the 314 requirement for the presence of a DNA sequence between position -41 and +61 to observe a 315 negative control by IscR $_{\mathrm{Cp}}$ of its own transcription in B. subtilis (Table 2). Interestingly, this 316 motif is very similar to the IscR binding sites of the $i s c R$ promoter regions of E. coli and $T$. 317 potens $[9,31]$ and is conserved in the $i s c R$ promoter regions of several clostridia (see 318 discussion). The alignment of the $i s c R$ promoters of E. coli, T. potens and C. perfringens and the 319 cpe2093 promoter allowed proposing a conserved motif, AWWGTTGACMAWWW320 TRMTSGGNWWT (Fig. 3SB). In all cases, this motif overlaps the -35 boxes of the promoters. 321 To confirm the involvement of this motif in $i s c R_{C p}$ regulation, two point mutations were 322 introduced in conserved nucleotides in this sequence. The PiscR-lacZ fusions containing 323 mutations were introduced at the amyE locus of a B. subtilis $\Delta c y m R$ thrC: $: \mathrm{P}_{\mathrm{xylA}}-i s c R_{C p}$ strain. 324 The level of $\beta$-galactosidase activity was determined after growth in the presence of methionine 325 or cystine (Table 2). The replacement of the $\mathrm{T}$ at position -22 by a $\mathrm{G}$ or the $\mathrm{G}$ at position -19 by a 326 A (Fig. 1) led to a partial derepression of $i s c R$ expression in the presence of cystine while in a double mutant (T-22G/G-19A), the expression of iscR was only two-fold repressed in the presence of cystine instead of 9-fold for the fusion containing the wild-type promoter region. These results are in agreement with a role of the conserved motif for the cystine-dependent repression of $i s c R_{C p}$, a repression mediated by $\operatorname{IscR}_{\mathrm{Cp}}$.

331 The RegPredict web-server [23] was subsequently used to search for similar DNA motifs and 332 reconstruct candidate IscR regulons in the genomes of 16 Clostridium spp. (Table S2). A 333 constructed positional-weight-matrix for the identified IscR-binding motif was applied to 334 upstream gene regions in the genomic sequences of clostridia to identify additional candidate 335 sites (Fig. 3). One or two copies of IscR motif were found upstream of the iscRSU gene cluster in each analyzed genome. We also identified a second potential IscR binding site located downstream of the transcriptional start site of $i s c R_{C p}$ (Fig. 1 and 3). Additional candidate sites were found upstream of the suf operons in C. acetobutylicum and C. kluyveri, and of the cysK gene in C. cellulolyticum and C. beijerinckii. Finally, we found additional IscR sites upstream of genes controlled by IscR $\mathrm{R}_{\mathrm{Cp}}$ in the obtained $C$. perfringens transcriptome (Table 3 ). These include potential IscR binding sites in the promoter regions of cpe0664 encoding an A type carrier for

342 Fe-S clusters biogenesis and the lactate dehydrogenase gene ldh (Fig. 3 and Table S2). We 343 mapped the promoters of cpe0664 and $l d h$ by RACE (Fig. S4). In both cases, the potential IscR 
344 binding site is located downstream from the transcriptional start site for $l d h$ or overlaps the -35

345 box for cpe0664. This is in agreement with the repression of their expression by IscR $\mathrm{R}_{\mathrm{Cp}}$.

\section{Discussion}

348 In E. coli and several other bacteria, genes involved in Fe-S cluster biogenesis are regulated in 349 response to $\mathrm{Fe}-\mathrm{S}$ availability through the $\mathrm{Fe}-\mathrm{S}$ regulatory protein IscR, and are induced during 350 iron starvation and oxidative stress [32]. By contrast, only few data are available concerning the control of Fe-S cluster synthesis in Gram-positive bacteria, in anaerobic bacteria [31] or in response to sulfur availability [11]. In $C$. perfringens, we have previously shown a coordinated regulation in response to cysteine availability of genes involved in Fe-S production (isc $S$, isc $U$, cpe0664) [1]. We demonstrate in this work that the $\mathrm{IscR}_{\mathrm{Cp}}$ repressor mediates this control. Other genes encoding transporters (Cpe2093-Cpe2092 and Cpe1371) that might be involved in supplying for sulfur required for $\mathrm{Fe}-\mathrm{S}$ biogenesis are also under the coordinated control of IscR $_{\mathrm{Cp}}$. These regulations may allow $C$. perfringens maintaining its pools of Fe-S clusters, which play a crucial role in the physiology of clostridia lacking the heme synthesis machinery [17]. Interestingly, $\mathrm{IscR}_{\mathrm{Cp}}$ also controls the expression of genes involved in fermentation pathways (Fig. 2) and we observe accordingly a decrease of butyrate production and a drastic increase of lactate production in the $i s c R$ mutant. The pyruvate to acetyl-CoA conversion is catalyzed by the pyruvate ferredoxin-oxido-reductase (PFOR). This Fe-S enzyme forms $\mathrm{CO}_{2}$ and acetyl-CoA by oxidizing pyruvate and reducing a $2 \mathrm{Fe}-4 \mathrm{~S}$ ferredoxin. This step implies the utilization of several Fe-S clusters while lactate production by the lactate dehydrogenase does not. So, we propose that during cysteine limitation [1], Isc $\mathrm{R}_{\mathrm{Cp}}$ could reroute the fermentation metabolism increasing $l d h$ expression to reoxidize the NADH produced during glycolysis and limiting the utilization of Fe$\mathrm{S}$ clusters. It is intriguing to note that in $C$. acetobutylicum, lactate production increases under conditions of iron limitation [4] while in C. perfringens ldh expression increases under conditions of sulfur limitation [1]. In both cases, IscR that is probably able to sense iron and sulfur availability might be involved in this control.

371 We then establish using ChIP experiments that $\mathrm{IscR}_{\mathrm{Cp}}$ directly interacts with the promoter region 372 of $i s c R_{C p}$ and of cpe2093 in vivo in C. perfringens. We further identify a conserved motif 373 overlapping the -35 boxes of these two promoters that share similarities with the IscR binding 374 motifs of E. coli, Erwinia chrysanthemi, Pseudomonas aeruginosa and T. potens [9, 28, 29, 31].

375 We also propose that a second site is present in the $i s c R$ promoter region of $C$. perfringens as observed in E. coli and T. potens. We further show that this motif is conserved upstream of iscR 
377

378

379

380

381

382

383

384

385

386

387

388

389

390

391

392

393

394

395

396

397

398

399

400

401

402

403

404

405

406

407

408

409

in clostridia (Fig. 3 and Table S2). For cpe0664 encoding an A-type scaffold protein involved in $\mathrm{Fe}-\mathrm{S}$ biogenesis and $l d h$, we identify DNA sequences located at position allowing repression (Fig. 3 and S4) that share similarities to the IscR $_{C p}$ binding motif. However, we fail to detect a clear binding of $\mathrm{IscR}_{\mathrm{Cp}}$ to the cpe0664 or the $l d h$ promoter region in vivo in our conditions. It is known that the binding of several proteins to a promoter region may lead to false negatives in ChIP experiments [20]. So, it is interesting to note that a Rex binding site is identified in the ldh promoter region [27] and we cannot exclude that interference might exist between IscR and Rex. In conclusion, in vitro experiments will be required to determine if IscR $_{\mathrm{Cp}}$ binds to the candidate IscR binding motifs in the cpe0664 and $l d h$ promoter regions. This will deserve further investigations.

Other genes involved in stress response, in metabolism or encoding proteins of unknown functions are regulated both by $\mathrm{IscR}_{\mathrm{Cp}}$ and in response to cysteine availability [1]. A second class of genes including cpe1031 encoding a regulator, genes involved in host compound utilization or encoding proteins of unknown function seems to be regulated only by $\mathrm{IscR}_{\mathrm{Cp}}$. In $E$. coli and probably also in $T$. potens, two classes of IscR-controlled genes with distinct binding motifs exist. Type I sites are only bound by IscR associated to a Fe-S cluster while type II sites interact both with Apo-IscR and IscR containing a Fe-S cluster [9, 22, 31, 32]. The possible existence of type II promoters in $C$. perfringens and the determination of direct or indirect regulation by $\mathrm{IscR}_{\mathrm{Cp}}$ for most of the IscR-controlled genes remain to be established and will deserve further investigations.

The IscR regulator is absent in aerobic firmicutes but is present in several clostridia. With a few exceptions, the $i s c R$ gene is in operon with iscS and isc $U$ (Fig. 3). The presence of an IscR binding motif upstream of these $i s c R$ operons strongly suggests a conserved mechanism of control of Fe-S cluster homeostasis in these clostridia. Interestingly, a putative iscR binding site is also present upstream of the suf operons in C. acetobutylicum and C. kluyveri. In $C$. acetobutylicum, the Isc system is probably absent while in C. kluyveri like in E. coli and T. potens, both the Isc and Suf machineries are present. In E. coli, the suf genes are positively controlled by IscR in aerobic conditions and IscR is able to bind to the suf promoter region in $E$. coli and $T$. potens through a type II binding site [9, 31]. Moreover, we also identify a potential IscR binding motif upstream of cysK of C. cellulolyticum and C. beijerinckii (Fig. 3 and Table $\mathrm{S} 2$ ). While the cys $K$ gene encoding the $O$-acetylserine-thiol-lyase in $C$. perfringens is induced under conditions of cysteine starvation through a cysteine specific T-box [1], the cys $K$ gene in $C$. cellulolyticum and C. beijerinckii might be under the control of IscR. Cysteine is the sulfur donor 
410 for Fe-S biogenesis and the possible existence of a coordinated regulation of the isc genes and 411 the cys $K$ gene might allow supplying for sulfur required for Fe-S production.

412 Finally, the control by $\mathrm{IscR}_{\mathrm{Cp}}$ of genes encoding proteins involved in host compound degradation 413 suggests that $\mathrm{IscR}_{\mathrm{Cp}}$ might play a role during the host colonization or the infection by $C$. 414 perfringens. This is in agreement with recent works showing that in several pathogenic Gram415 negative bacteria, IscR controls expression of factors involved in virulence or allowing 416 adaptation to hostile conditions encounters in the host $[18,28]$.

Acknowledgments. We are thankful to Olga Soutourina for helpful discussion. This research was supported by a grant from the Institut Pasteur (PTR $\mathrm{N}^{\circ} 256$ ). G. André was the recipient of a grant from the Ministère de l'enseignement supérieur et de la recherche and from the PasteurWeizmann foundation. D.Rodionov was supported by the Russian Foundation for Basic Research (14-04-91154).

\section{Figure legends}

426 Figure 1. $C$. perfringens cpe1786/isc $R_{\mathrm{Cp}}$ promoter region.

427 The initiation of transcription start site « $+1 »$ identified by 5 'RACE is indicated by an arrow. 428 The -10 and -35 boxes of the $\sigma^{\mathrm{A}}$-dependent promoter are underlined. The ribosome-binding site 429 is indicated in bold while the translational start site of cpe1786 is indicated in bold and italic. In 430 the genome of $C$. perfringens 13, the translational start codon of cpe1786 is a GTG 431 corresponding to a valine leading to a truncation of 25 amino acids and the absence of the $\alpha 1$ 432 helix of the wHTH motif (Fig. S2). We rather proposed the ATG preceded by a ribosome 433 binding site (GAGG). This start codon corresponds to the start of CPF_2040, the homologs of 434 Cpe1786 in the genome of C. perfringens ATCC 13124 [19]. Broken arrows indicate the end 435 points of the iscR-lacZ fusions. The conserved motif present upstream of the iscR genes in 436 clostridia is boxed. Point mutations obtained in this motif are indicated. A second potential IscR 437 binding motif (see Table S2) is over-lined.

438 Figure 2. Effect of isc $_{\mathbf{C p}}$ gene inactivation on fermentation pathways. (A) Genes involved in 439 fermentation pathways differentially expressed in an iscR mutant compared to strain 13. Arrows $440 \boldsymbol{\lambda}$ and $\boldsymbol{y}$ indicated genes whose expression increased or decreased in an iscR mutant compared 441 to strain 13. (B) Changes in metabolic end products in the C. perfringens strain 13 and the iscR 442 mutant. Chromatography analysis from theses two strains after $48 \mathrm{~h}$ of growth in minimal 443 medium containing cystine was performed. The mean and standard error of two experiments are 444 shown. 
445 Figure 3. Candidate IscR regulons reconstructed by comparative genomics approach in

446 Clostridia spp. (A) Chromosomal clusters of candidate IscR-regulon genes in Clostridia and

447 Thermincola potens. Homologous genes are marked by the same color. Potential IscR-binding

448 sites are shown by red arrows. (B) Consensus sequence logo of the predicted IscR-binding sites 449 in Clostridia. The logo was generated from the sequence alignments with WebLogo 450 (http://weblogo.berkeley.edu).

Table 1 Strains used in this study

\begin{tabular}{|c|c|c|}
\hline Strain & Genotype & Origin \\
\hline \multicolumn{3}{|l|}{ E. coli } \\
\hline DH5 & 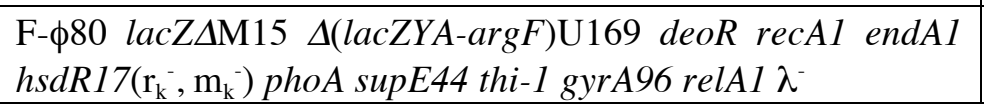 & Invitrogen \\
\hline Top10 & 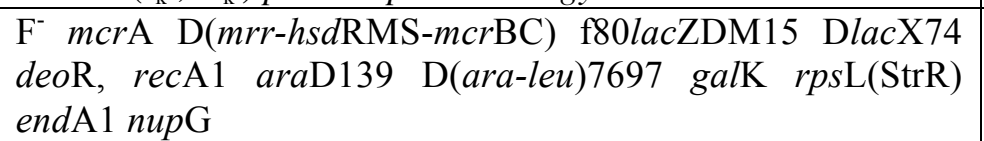 & Invitrogen \\
\hline \multicolumn{3}{|l|}{ B. subtilis } \\
\hline 168 & $\operatorname{trpC2}$ & Laboratory stock \\
\hline BSIP1798 & $\operatorname{trp} C 2 \Delta c y m R_{B s}$ amyE::aphA3 lacZ & [7] \\
\hline BSIP1978 & $\operatorname{trp} C 2 \Delta \operatorname{cym} R_{B s}$ amyE $: \mathrm{P}(-131+61)$ isc $R_{C p}$-lacZ cat & pDIA5820 $\rightarrow$ BSIP1798 \\
\hline BSIP1981 & 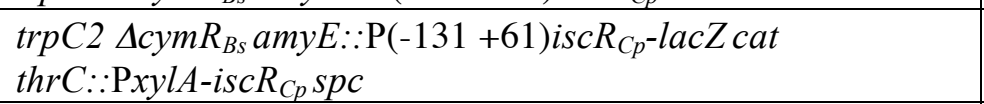 & pDIA5744 $\rightarrow$ BSIP1978 \\
\hline BSIP2018 & $\operatorname{trpC2} \Delta c y m R_{B s}$ amyE $:: a p h A 3$ lacZ thrC::PxylA-iscR $R_{C p} s p c$ & PAC7 $\rightarrow$ BSIP1981 \\
\hline BSIP2020 & 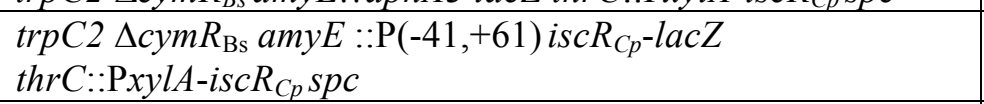 & PDIA5837 $\rightarrow$ BSIP2018 \\
\hline BSIP2022 & $\begin{array}{l}\operatorname{trp} C 2 \Delta c y m R_{\mathrm{Bs}} \text { amyE }:: \mathrm{P} i s c R_{C p} \mathrm{~T}-22 \mathrm{G}-\text { lacZ cat thrC::PxylA- } \\
\text { iscR }_{C p} \operatorname{spc}\end{array}$ & pDIA5840 $\rightarrow$ BSIP2018 \\
\hline BSIP2024 & $\begin{array}{l}\operatorname{trp} C 2 \Delta c y m R_{\mathrm{Bs}} \text { amyE }:: \mathrm{P} i s c R_{C p} \mathrm{G}-19 \mathrm{~A}-l a c Z \text { cat } \\
\text { thrC }:: \mathrm{P} x y l A-i s c R_{C p} s p c\end{array}$ & pDIA5842 $\rightarrow$ BSIP2018 \\
\hline BSIP2029 & 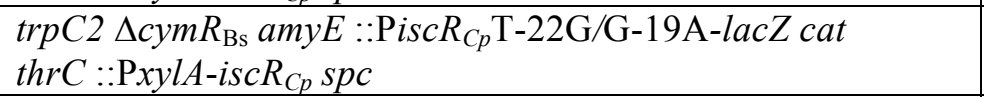 & pDIA5846 $\rightarrow$ BSIP2018 \\
\hline \multicolumn{3}{|l|}{ C. perfringens } \\
\hline 13 & Wild-type & [34] \\
\hline CPIP01 & cpe1786/iscR::erm & $\begin{array}{l}\text { pMTL007-Cpe1786-28a } \\
\rightarrow \text { strain } 13\end{array}$ \\
\hline CPIP11 & cpe1786/iscR::erm pDIA5928-iscR-Xflag & pDIA5928 $\rightarrow$ CPIP01 \\
\hline \multicolumn{3}{|l|}{ Plasmids } \\
\hline pMTL007 & $\begin{array}{l}\text { group II intron, ErmBtdRAM2 and ltrA } \text { ORF from } \\
\text { pMTL20lacZTTErmBtdRAM2, } \mathrm{Cm}^{\mathrm{R}} / \mathrm{Tm}^{\mathrm{R}}\end{array}$ & [12] \\
\hline pMTL83151 & PCB102 replicon, $\mathrm{Cm}^{\mathrm{R}}$ & [13] \\
\hline pAC6 & & [38] \\
\hline pXT & $A p^{R}, S^{R}$ & [21] \\
\hline $\begin{array}{l}\text { pMTL007- } \\
\text { cpe1786-28a }\end{array}$ & $\mathrm{Cm}^{\mathrm{R}} / \mathrm{Tm}^{\mathrm{R}}$ & This work \\
\hline pDIA5744 & pXT-iscR $R_{C p}$ & This work \\
\hline pDIA5820 & pAC6 P(-131, +61) isc $R_{C p}-l a c Z$ & This work \\
\hline pDIA5837 & pAC6 P(-41, +61) iscR $R_{C p}-l a c Z$ & This work \\
\hline pDIA5840 & pAC6 P(-131 +61) T-22G iscR $R_{C p}-l a c Z$ & This work \\
\hline pDIA5842 & pAC6 P(-131 +61) G-19A iscR $R_{C p}-l a c Z$ & This work \\
\hline pDIA5846 & pAC6 P(-131 +61) T-22G / G-19A iscR $R_{C p}$-lacZ & This work \\
\hline
\end{tabular}




\begin{tabular}{|l|l|l|}
\hline pDIA5852 & pAC6 P(-131 +61) T-15C $i s c R_{C p}$-lacZ & This work \\
\hline pDIA5925 & pGEMTeasy- $i s c R$-XFlag & This work \\
\hline pDIA5928 & pGEMTeasy/pCB3 replicon/cat- iscR-XFlag & This work \\
\hline
\end{tabular}

454 (2) cat, erm and $s p c$ encode proteins leading to chloramphenicol (Cm), erythromycin (Em) or spectinomycin (Sp)

455 resistance. Tm corresponds to thiamphenicol.

456 (3) the arrow indicates a construction by transformation

Table 2. Regulation of isc $_{\mathrm{Cp}}$ expression by $\mathrm{IscR}_{\mathrm{Cp}}$ in $B$. subtilis.

\begin{tabular}{|c|c|c|c|}
\hline \multirow[t]{2}{*}{ Strain } & \multirow[t]{2}{*}{ Relevant genotype } & \multicolumn{2}{|c|}{$\begin{array}{l}\beta \text {-galactosidase activity (nmol } \\
\mathrm{ONP} / \mathrm{min} / \mathrm{mg} \text { of protein) }\end{array}$} \\
\hline & & Methionine & Cystine \\
\hline BSIP1978 & $\Delta c y m R_{\mathrm{Bs}}$ amyE $:: \mathrm{P}(-131,+61) i s c R_{C p}$-lacZ & $1070+/-90$ & $1025+/-60$ \\
\hline BSIP1981 & $\begin{array}{l}\Delta c y m R_{\mathrm{Bs}} \text { amyE }:: \mathrm{P}(-131,+61) i s c R_{C p}-l a c Z \text { thrC }:: \mathrm{P} x y l- \\
i_{s c R_{C p}}\end{array}$ & $1085+/-2$ & $115+/-20$ \\
\hline BSIP2020 & $\begin{array}{l}\Delta c y m R_{\mathrm{Bs}} \text { amyE }:: \mathrm{P}(-41,+61) \text { iscR } R_{C p} \text {-lacZ thrC ::Pxyl- } \\
i_{s c R_{C p}}\end{array}$ & $730+/-17$ & $58.5+/-1.5$ \\
\hline BSIP2022 & $\begin{array}{l}\Delta c y m R_{\mathrm{Bs}} \text { amyE }:: \mathrm{P}(-131,+61) \text { iscR } R_{C p}-\mathrm{T}-22 \mathrm{G}-l a c Z \\
\text { thrC }:: \mathrm{Pxyl} \text {-isc } R_{C p}\end{array}$ & $1025+/-30$ & $370+/-20$ \\
\hline BSIP2024 & $\begin{array}{l}\Delta c y m R_{\mathrm{Bs}} \text { amyE }:: \mathrm{P}(-131,+61) i s c R_{C p} \text {-G-19A-lacZ } \\
\text { thrC }:: \mathrm{Pxyl} \text {-isc } R_{C p}\end{array}$ & $1070+/-30$ & $380+/-5$ \\
\hline BSIP2029 & $\begin{array}{l}\Delta c y m R_{\mathrm{Bs}} \text { amy } E:: \mathrm{P}(-131,+61) i s c R_{C p}-\mathrm{T}-22 \mathrm{G} / \mathrm{G}-19 \mathrm{~A}-l a c Z \\
\text { thrC }:: \mathrm{P} x y l-i s c R_{C p}\end{array}$ & $1050+/-24$ & $515+/-10$ \\
\hline
\end{tabular}

$\beta$-galactosidase activity was mesured on crude extracts from strains grown in minimal medium in the presence of 1 $\mathrm{mM}$ methionine or $1 \mathrm{mM}$ cystine. isc $R \mathrm{Cp}=$ cpe1786. For strains BSIP1981, BSIP2020, BSIP2022, BSIP2024 and BSIP2029 0.1\% xylose and $50 \mathrm{mg} / \mathrm{L}$ of threonine were added.

Table 3. Genes differentially expressed between strain 13 of $C$. perfringens and a isc $R_{\mathrm{Cp}}$ mutant.

\begin{tabular}{|c|c|c|c|}
\hline \multirow[t]{2}{*}{$\begin{array}{c}\text { gene } \\
\text { (Synonym) }\end{array}$} & \multirow[t]{2}{*}{ Functions/similarities } & Transcriptome & $\begin{array}{c}\text { quantitative } \\
\text { RT-PCR } \\
\end{array}$ \\
\hline & & $i s c R_{\mathbf{C p}} / 13$ & $i s c R_{\mathbf{C p}} / 13$ \\
\hline \multicolumn{4}{|c|}{ Fe-S clusters and redox functions } \\
\hline сре0664 & HesB-like protein (114 aa) & 12.5 & 27 \\
\hline cpe1785 (iscS) & $\begin{array}{l}\text { Cysteine desulfurase, Fe-S clusters } \\
\text { biosynthesis }\end{array}$ & 2.1 & \\
\hline cpe1784 (iscU) & Fe-S clusters assembly & 2 & \\
\hline cpe1783 (trmU) & $\begin{array}{l}\text { Methylaminomethyl-2-Thiouridylate- } \\
\text { Methyltransferase }\end{array}$ & 2 & \\
\hline cpe2511(fer) & Ferredoxin [3Fe-4S] & 0.29 & 0.2 \\
\hline сре0855 (rubY) & rubrerythrin & 0.17 & \\
\hline \multicolumn{4}{|c|}{ Transporters, membrane or exported proteins } \\
\hline cpe2092 & $\begin{array}{l}\text { Amino acid ABC transporter, ATP } \\
\text { binding cassette }\end{array}$ & 10.2 & 26 \\
\hline cpe2093 & Amino acid ABC transporter, permease & 5.5 & \\
\hline cpe2295 (lepW) & Type I Signal peptidase & 6.6 & \\
\hline cpe1371 & $\mathrm{Na}+$-dependent symporter & 3.6 & 7.5 \\
\hline cpe1621 & putative cation efflux protein & 3.4 & \\
\hline cpe1343 & probable galactoside $\mathrm{ABC}$ transporter & 0.1 & \\
\hline cpe1341 & probable galactoside $\mathrm{ABC}$ transporter & 0.21 & \\
\hline \multicolumn{4}{|l|}{ Regulators } \\
\hline cpe1031 & ArsR-SmtB family regulator & 7.8 & 20 \\
\hline
\end{tabular}




\begin{tabular}{|c|c|c|c|}
\hline cpe2304 & ArsR-SmtB family regulator & 1.99 & \\
\hline \multicolumn{4}{|c|}{ Carbon metabolism } \\
\hline cpe0103 (ldh) & L-lactate dehydrogenase & 38.6 & 130 \\
\hline cpe2531(adhE) & Aldehyde alcohol dehydrogenase & 3.03 & \\
\hline cpe2195 (atoB) & Acetyl-CoA acetyltransferase & 0.13 & \\
\hline cpe2297 & 3-hydroxybutyryl-CoA dehydrogenase & 0.163 & \\
\hline cpe2298 (fixB) & $\alpha$ subunit electron transfer flavoprotein & 0.22 & \\
\hline cpe2299 (etfB) & $\beta$ subunit electron transfer flavoprotein & 0.29 & \\
\hline cpe2300 (bcd) & Acyl-CoA dehydrogenase & 0.21 & \\
\hline cpe2301 (crt) & 3-hydroxybutyryl-CoA dehydratase & 0.33 & 0.5 \\
\hline сре0892 & $\begin{array}{l}\text { butanol dehydrogenase NADPH } \\
\text { dependent }\end{array}$ & 0.618 & \\
\hline cpe2347 (buk) & butyrate kinase & 0.63 & \\
\hline cpe2348 (ptb) & phosphotransbutyrylase & 0.625 & \\
\hline cpe1185 (pfk) & 6-phophofructokinase & 0.5 & \\
\hline cpe1299 (eno) & enolase & 0.54 & \\
\hline cpe2149 (pykA) & Pyruvate kinase & 0.59 & \\
\hline cpe2267 & glucose-6-phosphate isomerase & 1.65 & \\
\hline cpe1463 & PTS system IID component (IIDMan) & 2.2 & \\
\hline cpe1464 & PTS system IIC component (IICMan) & 1.45 & \\
\hline cpe 1465 & PTS system IIB component (IIDMan) & 1.53 & \\
\hline cpe1466 & PTS system IIA component (IIAMan) & 2.65 & \\
\hline cpe1873(manB) & phosphomannomutase & 1.587 & \\
\hline \multicolumn{4}{|c|}{ Other metabolisms } \\
\hline cpe1050 & 5'-MTA/SAH nucleosidase & 3.8 & \\
\hline cpe0056 & 5'-MTA/SAH nucleosidase & 1.58 & \\
\hline cpe1573 & Probable glutamate cysteine ligase & 2.9 & \\
\hline cpe0447 (lguL) & Lactoylglutathione lyase & 2 & \\
\hline \multicolumn{4}{|c|}{ Host compounds degradation } \\
\hline cpe0818 & endo- $\beta$-N-acetyl-glucosaminidase & 9.9 & 16 \\
\hline cpe0866 & $\alpha-\mathrm{N}$-acetyl-glucosaminidase & 5.8 & 15 \\
\hline cpe1523 (nagL) & hyaluronidase & 3.8 & 8.8 \\
\hline \multicolumn{4}{|c|}{ Unknown function } \\
\hline cpe0554 & Unknown & 6.7 & \\
\hline cpe2261 & Unknown & 5.3 & \\
\hline cpe2262 & Unknown & 4.35 & \\
\hline cpe2063 & Unknown & 5.2 & \\
\hline cpe1079 & Unknown & 5.2 & \\
\hline cpe1257 & Unknown & 4.6 & \\
\hline cpe1875 & Unknown & 4.3 & \\
\hline cpe0106 & Unknown & 3.5 & \\
\hline сре0105 & Unknown & 3.15 & \\
\hline cpe1169 & Unknown & 3.42 & \\
\hline cpe1735 & Unknown & 3.66 & \\
\hline cpel173 & Unknown & 0.15 & \\
\hline сре2111 & Unknown & 0.26 & \\
\hline cpe 1078 & Unknown & 0.27 & \\
\hline сре0098 & Unknown & 0.29 & \\
\hline cpe1472 & Unknown & 0.29 & \\
\hline
\end{tabular}

466 Gene names and functions correspond to those indicated in the GenoList data-base 467 (http://genodb.pasteur.fr/cgi-bin/WebObjects/GenoList). A gene was considered as differentially 468 expressed when the p-value is $<0.05$ using the statistical analysis described in Materials and 
Methods. Controlled genes with expression ratio above three-fold between strains 13 and $i s c R_{\mathbf{C p}}$ and those associated with iron-sulfur clusters biogenesis, redox functions, carbon and sulfur metabolisms and the degradation of host compounds are presented in this Table. We confirmed the transcriptome data by qRT-PCR analysis for several genes.

\section{References}

[1] Andre G, Haudecoeur E, Monot M, Ohtani K, Shimizu T, Dupuy B, et al. Global regulation of gene expression in response to cysteine availability in Clostridium perfringens. BMC Microbiol 2010;10:234.

[2] Antunes A, Camiade E, Monot M, Courtois E, Barbut F, Sernova NV, et al. Global transcriptional control by glucose and carbon regulator CcpA in Clostridium difficile. Nucleic acids research 2012;40:10701-18.

[3] Ayala-Castro C, Saini A, Outten FW. Fe-S cluster assembly pathways in bacteria. Microbiol Mol Biol Rev 2008;72:110-25, table of contents.

[4] Bahl H, Gottwald M, Kuhn A, Rale V, Andersch W, Gottschalk G. Nutritional Factors Affecting the Ratio of Solvents Produced by Clostridium acetobutylicum. Appl Environ Microbiol 1986;52:169-72.

[5] Burguiere P, Auger S, Hullo MF, Danchin A, Martin-Verstraete I. Three different systems participate in L-cystine uptake in Bacillus subtilis. J Bacteriol 2004;186:4875-84.

[6] Carlier JP, Sellier N. Gas chromatographic-mass spectral studies after methylation of metabolites produced by some anaerobic bacteria in spent media. J Chromatogr 1989;493:25773.

[7] Even S, Burguiere P, Auger S, Soutourina O, Danchin A, Martin-Verstraete I. Global control of cysteine metabolism by CymR in Bacillus subtilis. J Bacteriol 2006;188:2184-97. [8] Fleischhacker AS, Stubna A, Hsueh KL, Guo Y, Teter SJ, Rose JC, et al. Characterization of the [2Fe-2S] cluster of Escherichia coli transcription factor IscR. Biochemistry 2012;51:4453-62.

[9] Giel JL, Rodionov D, Liu M, Blattner FR, Kiley PJ. IscR-dependent gene expression links iron-sulphur cluster assembly to the control of O2-regulated genes in Escherichia coli. Mol Microbiol 2006;60:1058-75.

[10] Grundy FJ, Henkin TM. The T box and S box transcription termination control systems. Front Biosci 2003;8:20-31. [11] Gyaneshwar P, Paliy O, McAuliffe J, Popham DL, Jordan MI, Kustu S. Sulfur and nitrogen limitation in Escherichia coli K-12: specific homeostatic responses. J Bacteriol 2005;187:1074-90.

[12] Heap JT, Pennington OJ, Cartman ST, Carter GP, Minton NP. The ClosTron: a universal gene knock-out system for the genus Clostridium. J Microbiol Methods 2007;70:452-64. [13] Heap JT, Pennington OJ, Cartman ST, Minton NP. A modular system for Clostridium shuttle plasmids. J Microbiol Methods 2009;78:79-85.

[14] Ito S, Muramatsu T, Kobata A. Endo-beta-N-acetylglucosaminidases acting on carbohydrate moieties of glycoproteins: purification and properties of the two enzymes with different specificities from Clostridium perfringens. Arch Biochem Biophys 1975;171:78-86. [15] Johnston AW, Todd JD, Curson AR, Lei S, Nikolaidou-Katsaridou N, Gelfand MS, et al. Living without Fur: the subtlety and complexity of iron-responsive gene regulation in the symbiotic bacterium Rhizobium and other alpha-proteobacteria. Biometals 2007;20:501-11. [16] Livak KJ, Schmittgen TD. Analysis of relative gene expression data using real-time quantitative PCR and the 2(-Delta Delta C(T)) Method. Methods 2001;25:402-8.

[17] Meyer J. Clostridial iron-sulphur proteins. J Mol Microbiol Biotechnol 2000;2:9-14. 
[18] Miller HK, Auerbuch V. Bacterial iron-sulfur cluster sensors in mammalian pathogens. Metallomics 2015;7:943-56.

[19] Myers GS, Rasko DA, Cheung JK, Ravel J, Seshadri R, DeBoy RT, et al. Skewed genomic variability in strains of the toxigenic bacterial pathogen, Clostridium perfringens. Genome Res 2006;16:1031-40.

[20] Myers KS, Park DM, Beauchene NA, Kiley PJ. Defining bacterial regulons using ChIPseq. Methods 2015;86:80-8.

[21] Nair S, Derre I, Msadek T, Gaillot O, Berche P. CtsR controls class III heat shock gene expression in the human pathogen Listeria monocytogenes. Mol Microbiol 2000;35:800-11. [22] Nesbit AD, Giel JL, Rose JC, Kiley PJ. Sequence-specific binding to a subset of IscRregulated promoters does not require IscR Fe-S cluster ligation. J Mol Biol 2009;387:28-41. [23] Novichkov PS, Kazakov AE, Ravcheev DA, Leyn SA, Kovaleva GY, Sutormin RA, et al. RegPrecise 3.0--a resource for genome-scale exploration of transcriptional regulation in bacteria. BMC Genomics 2013;14:745.

[24] Ohtani K, Hirakawa H, Tashiro K, Yoshizawa S, Kuhara S, Shimizu T. Identification of a two-component VirR/VirS regulon in Clostridium perfringens. Anaerobe 2010;16:258-64. [25] Ohtani K, Takamura H, Yaguchi H, Hayashi H, Shimizu T. Genetic analysis of the ycgJmetB-cysK-ygaG operon negatively regulated by the VirR/VirS system in Clostridium perfringens. Microbiol Immunol 2000;44:525-8.

[26] Okumura K, Ohtani K, Hayashi H, Shimizu T. Characterization of genes regulated directly by the VirR/VirS system in Clostridium perfringens. J Bacteriol 2008;190:7719-27.

[27] Ravcheev DA, Li X, Latif H, Zengler K, Leyn SA, Korostelev YD, et al. Transcriptional regulation of central carbon and energy metabolism in bacteria by redox-responsive repressor Rex. J Bacteriol 2012;194:1145-57.

[28] Rincon-Enriquez G, Crete P, Barras F, Py B. Biogenesis of Fe/S proteins and pathogenicity: IscR plays a key role in allowing Erwinia chrysanthemi to adapt to hostile conditions. Mol Microbiol 2008;67:1257-73.

[29] Romsang A, Duang-Nkern J, Leesukon P, Saninjuk K, Vattanaviboon P, Mongkolsuk S. The iron-sulphur cluster biosynthesis regulator IscR contributes to iron homeostasis and resistance to oxidants in Pseudomonas aeruginosa. PLoS One 2014;9:e86763.

[30] Rood JI. Virulence genes of Clostridium perfringens. Ann Rev Microbiol1998;52:333-60. [31] Santos JA, Alonso-Garcia N, Macedo-Ribeiro S, Pereira PJ. The unique regulation of ironsulfur cluster biogenesis in a Gram-positive bacterium. Proc Natl Acad Sci U S A 2014;111:E2251-60.

[32] Santos JA, Pereira PJ, Macedo-Ribeiro S. What a difference a cluster makes: The multifaceted roles of IscR in gene regulation and DNA recognition. Biochim biophys acta 2015;1854:1101-12.

[33] Schwartz CJ, Giel JL, Patschkowski T, Luther C, Ruzicka FJ, Beinert H, et al. IscR, an Fe$\mathrm{S}$ cluster-containing transcription factor, represses expression of Escherichia coli genes encoding Fe-S cluster assembly proteins. Proc Natl Acad Sci U S A 2001;98:14895-900. [34] Shimizu T, Ohtani K, Hirakawa H, Ohshima K, Yamashita A, Shiba T, et al. Complete genome sequence of Clostridium perfringens, an anaerobic flesh-eater. Proc Natl Acad Sci USA 2002;99:996-1001.

[35] Shimizu T, Shima K, Yoshino K, Yonezawa K, Hayashi H. Proteome and transcriptome analysis of the virulence genes regulated by the VirR/VirS system in Clostridium perfringens. $\mathrm{J}$ Bacteriol 2002;184:2587-94.

[36] Shimizu T, Yaguchi H, Ohtani K, Banu S, Hayashi H. Clostridial VirR/VirS regulon involves a regulatory RNA molecule for expression of toxins. Mol Microbiol 2002;43:257-65. 
[37] Soutourina O, Poupel O, Coppee JY, Danchin A, Msadek T, Martin-Verstraete I. CymR, the master regulator of cysteine metabolism in Staphylococcus aureus, controls host sulfur source utilization and plays a role in biofilm formation. Mol Microbiol 2009;73:194-211. [38] Stülke J, Martin-Verstraete I, Zagorec M, Rose M, Klier A, Rapoport G. Induction of the Bacillus subtilis pts GHI operon by glucose is controlled by a novel antiterminator, GlcT. Mol Microbiol 1997;25:65-78.

[39] Tanous C, Soutourina O, Raynal B, Hullo MF, Mervelet P, Gilles AM, et al. The CymR regulator in complex with the enzyme CysK controls cysteine metabolism in Bacillus subtilis. $\mathrm{J}$ Biol Chem 2008;283:35551-60.

[40] Tucker NP, Le Brun NE, Dixon R, Hutchings MI. There's NO stopping NsrR, a global regulator of the bacterial NO stress response. Trends Microbiol 2010;18:149-56.

[41] Vinella D, Brochier-Armanet C, Loiseau L, Talla E, Barras F. Iron-sulfur (Fe/S) protein biogenesis: phylogenomic and genetic studies of A-type carriers. PLoS Genet 2009;5:e1000497.

\section{Supplementary data}

Figure S1. Genetic organization of the cpe1786/iscR locus and inactivation of the cpe1786 gene. The ClosTron delivery system (A) encoded on plasmid pMTL007 consists of a group II intron (black arrow) with an internal Retrotransposition-Activated Marker (RAM) conferring erythromycin resistance (white arrow) that is itself interrupted by the $t d$ group I intron (hatched box) [12]. The group II intron is retargeted to the cpel786 gene (grey arrow) by altering the sequence of the IBS/EBS region using overlap PCR. Splicing of the group II intron into cpe1786 disrupts it and the splicing out of the $t d$ group I intron from the erm RAM restores a functional ermB gene allowing positive selection of cpe 1786 mutants. B) Analysis of genetic organization of the cpe 1786 locus by RT-PCR experiments. cDNA were synthesized using RNA extracted from cells grown in the presence of homocysteine. Couples of primers used for PCRs are indicated in panel A. Agarose gel corresponds to the migration of the different PCR fragments obtained from RNA without (lane 1,3,5) or with (lane 2,4,6) a reverse transcriptase treatment. Lane 1 and 2: IMV489-IMV490, lane 3 and 4: GA54-IMV491, lane 5 and 6: IMV492-493.

C) Confirmation of cpe1786 knockout by PCR was performed using chromosomal DNA of $C$. perfringens CP13 (lane 1, 3 and 5) or an erythromycin resistant clones containing an intron in the cpe1786 gene (lane 2, 4 and 6) and the primer pairs RAM-F/RAM-R (lane 1 and 2), IMV485/EBSu (lane 3 and 4) and IMV485-IMV484. PCR products were visualized on 1\% w/v agarose gel.

Figure S2. Alignment of CymR and IscR-type regulators. The alignments were performed using the CLUSTALW algorithm. SA: Staphyloccoccus aureus; BS: B. subtilis; CA: C. acetobutylicum; CP: C. perfringens; CD: C. difficile; TP: Thermincola potens; EC: E. coli; ERWCT: Erwinia carotovora. The winged helix-turn-helix (HTH) motif is indicated by a blue 
603 arrow and the amino acids shown to interact with DNA of type 2 sites in E. coli are underlined.

604 The Glutamate at position 43 proposed to be involved in discrimination between type 2 and

605 type 1 site is indicated in blue. The region containing the Fe-S binding motif corresponds to the

606 red arrow. The 3 conserved cysteine residues coordinating the Fe-S cluster are indicated in red

607 while the histidine residue involved in Fe-S coordination in E. coli is indicated in green [8].

608 Figure S3. The iscR and $\operatorname{cym} \boldsymbol{R}$ operons. A. Comparison of the genetic organization of the 609 cpe1786 operon of $C$. perfringens with that of the cymR operon of B. subtilis and the iscR 610 operons of E. coli and T. potens. Genes encoding regulators are indicated by blue arrows. The \% 611 of identity between each regulator and Cpe1786 is indicated. B. IscR binding motif. Alignment 612 of IscR sites experimentally validated in E. coli [9], T. potens [31] and C. perfringens (this 613 work). The -35 boxes are underlined. The promoters have been mapped for iscR and yadR of $E$. 614 coli [9] and iscR of C. perfringens (Fig 1).

615 Figure S4. Mapping of $\boldsymbol{l d h}$ and $\boldsymbol{c p e 0 6 6 4}$ promoters by 5'RACE. The promoters region of $l d h$ 616 (сpe0103) and cpe0664 encoding an A-type scaffold protein for Fe-S assembly are presented. 617 The ATG of $l d h$ and cpe0664 are indicated in green. The ribosome bonding sites (RBS) are 618 underlined and the -10 and -35 corresponding to SigA consensus are boxed. The IscR binding 619 motifs identified using Reg-Predict [23] are indicated by blue arrows. In the case of cpe0664, a 620 second motif with a score $<5$ is also indicated.

621 Table S1. List of oligonucleotides

622 Table S2. Genomic identification of candidate IscR-binding sites in Clostridia spp. 
$\longmapsto-131$

GAATATTATAAGCCTAAGGATAATAAATACGAAAGTAGTATAAAAGCCTACTGGAATAAT GTAAAAAACAAATAGTTGAATTTCAATTTTAAATTCCATTTTTTAAGTAAAAAATATGTG

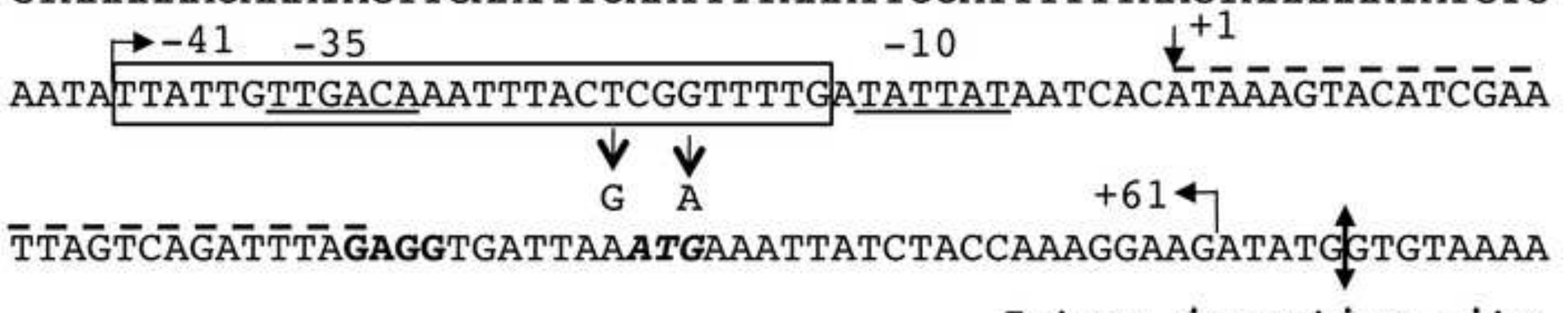
Intron insertion site 
Figure
Click here to download high resolution image

A

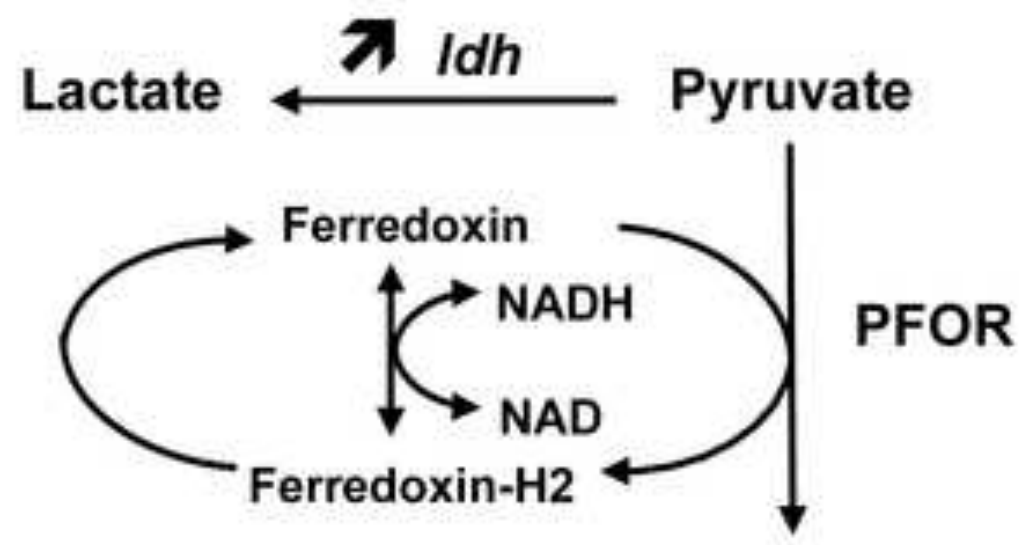

Acetyl-CoA $\underline{\text { a adh }} \underset{-}{\rightarrow}$ Ethanol

$y\left\{\begin{array}{c}a t o B \\ c p e 2297 \\ c r t \\ b c d\end{array}\right.$

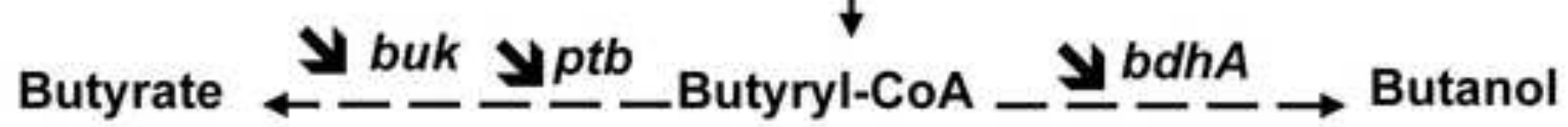

B

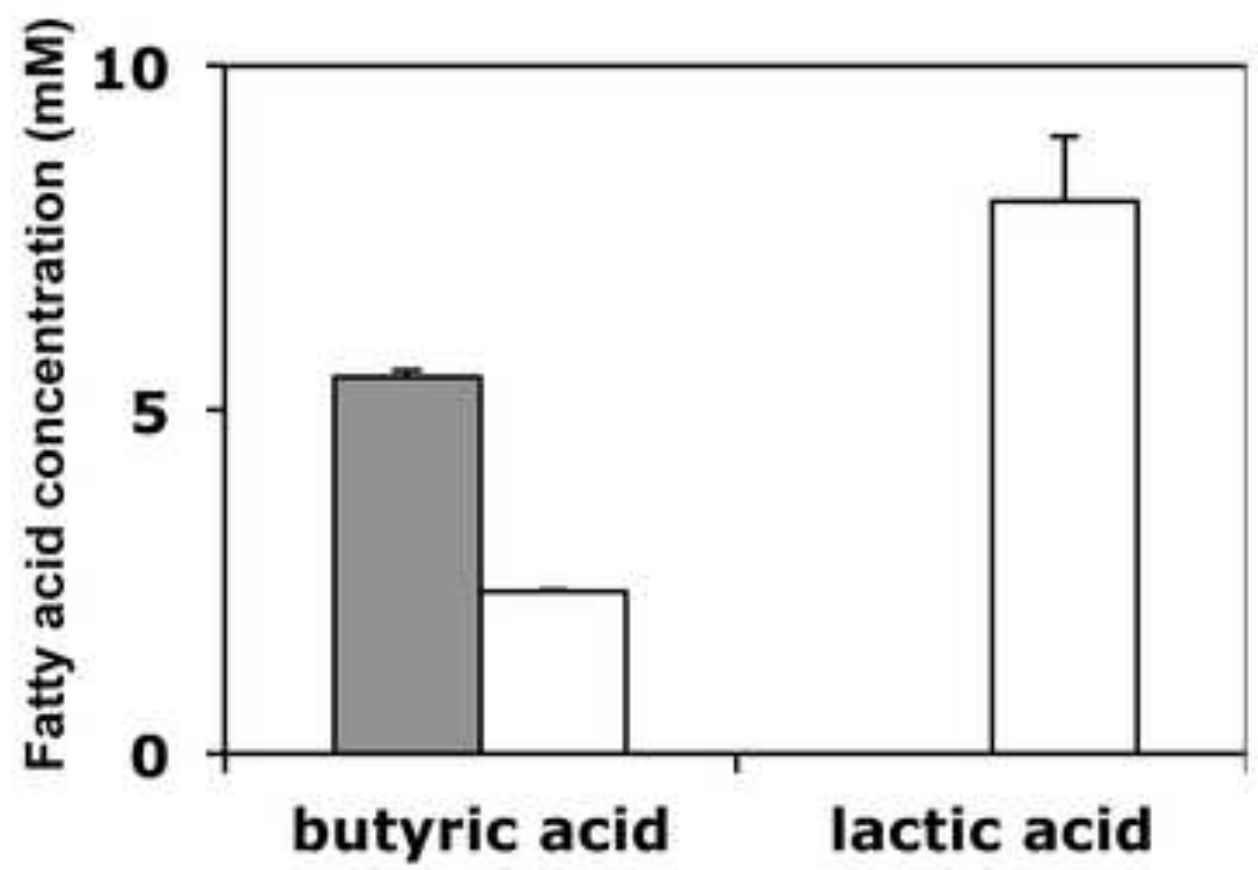


Click here to download high resolution image
A
C. perfringens
C. botulinum
C. butyricum
C. difficile
C. kluyveri
C. novyi
C. tetani
C. acetobutylicum
C. beijerincki
C. cellulolyticum

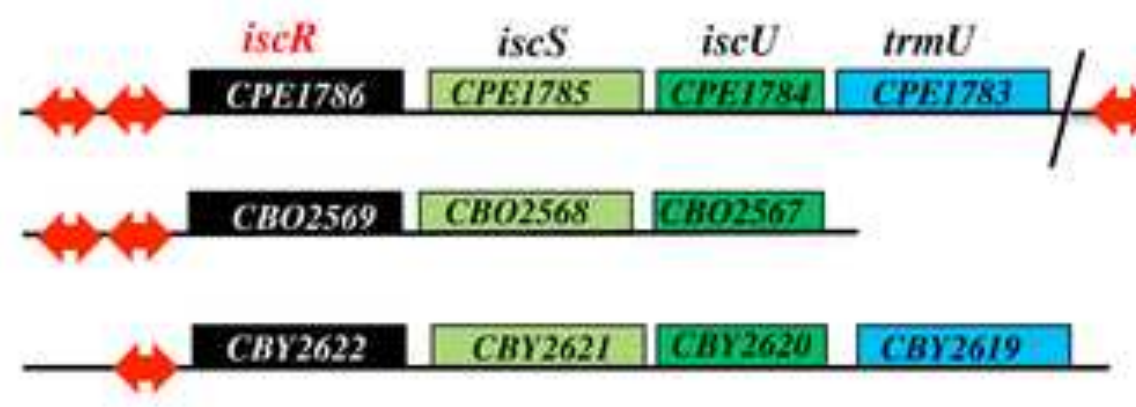
CDI278
\begin{tabular}{lll} 
CDI279 & CD1280 & CDI281 \\
\hline
\end{tabular}

\begin{tabular}{|c|c|c|}
\hline CKLIBI7 & CKL1318 & CKLII319 \\
\hline
\end{tabular}
sufC
ldh
PEO103
CPE0664
CPE2093-92
NT01CX2284 NT01CX 2283] NT01CX2281 NT01CX2280

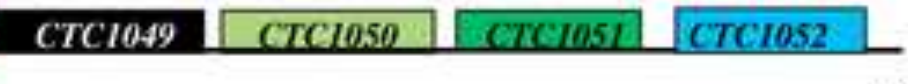

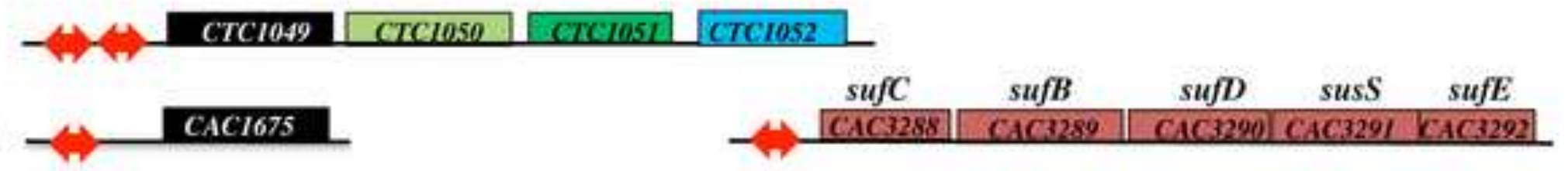
Thermincola potens 4 TherIRI9I4 TherJRI913 ThearIRI912 TherJIRI911
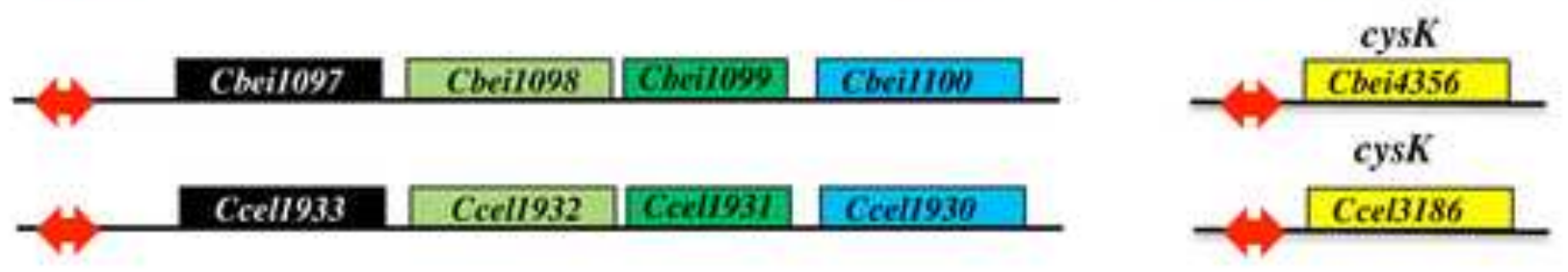

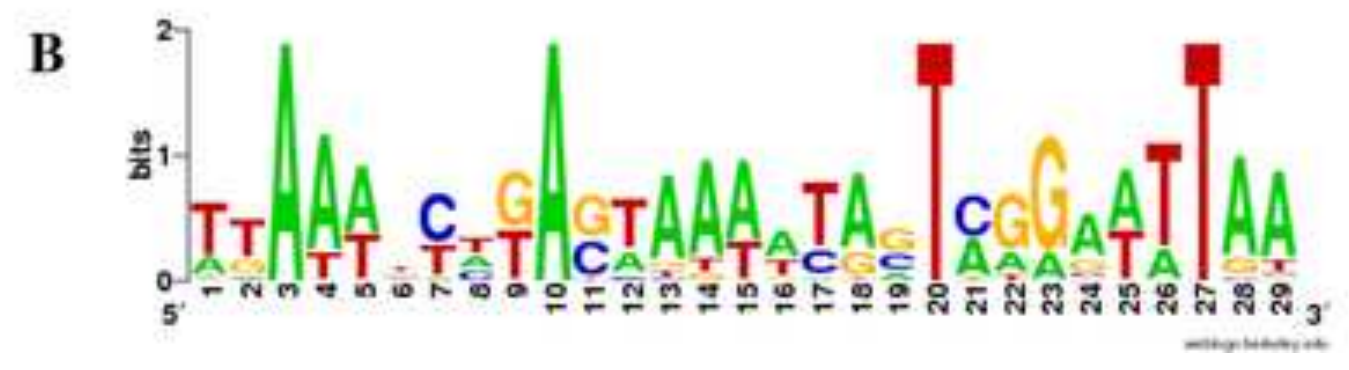




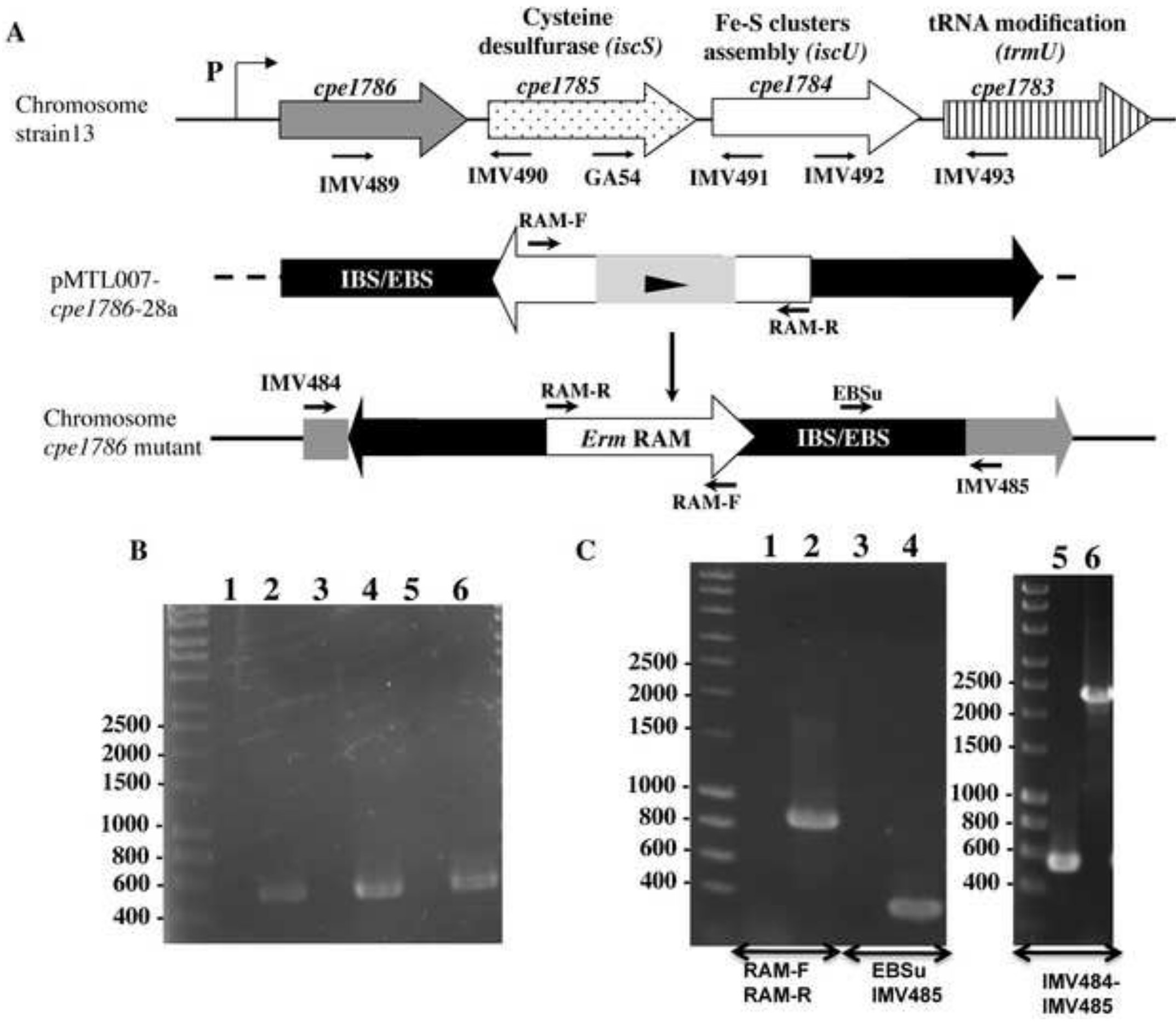


CymR-SA

CYmR-BS

ISCR-TP

CAC1675-CA

Cpe1786-CP

CD1278-CD

ISCR-ERWCT

ISCR-EC

CymR-SA

CYmR-BS

ISCR-TP

CAC1675-CA

Cpe1786-CP

CD1278-CD

ISCR-ERWCT

ISCR-EC

CymR-SA

CYmR-BS

ISCR-TP

CAC1675-CA

Cpe1786-CP

CD1278-CD

ISCR-ERWCT

IsCR-EC winged $\mathrm{HTH}$ motif

$\alpha 1$

$\alpha 2$

$\alpha 3$

$\beta 1$

MKISTKGRYGLTLMISLAKKEGQGCISLKSIAEENNLSDLYLEQLVGPLRNAGLIRSVR MLKISTKGRYGLTIMIELAKKHGEGPTSLKSIAQTNNLSEHYLEQLVSPLRNAGLVKSIR MKVSTKGHYGVQAMFDLAQHFGEGPVSLKSIAERQGLSEPYLEQLIAVLRKAGLVKSVR MKLSTKGRYGVKAMVDLAIHYGAEPVSIKSISERQKISEAYLEQLFVPLRKSGLIKSIR MKLSTKGRYGVKAMVDLAIHYGGSPVSIKSISQRQNISEYYLEQLFSSLRKAKLIKSIR MKLSTKGRYGLKAMFELALNQDNGPVSLKFIAKKQKISDQYLEQIFSSLKKSGLVKSVR MRLTSKGRYAVTAMLDVALHSQEGPVPLADISERQGISLSYLEQLFSRLRKNGLVASVR MRLTSKGRYAVTAMLDVALNSEAGPVPLADISERQGISLSYLEQLFSRLRKNGLVSSVR

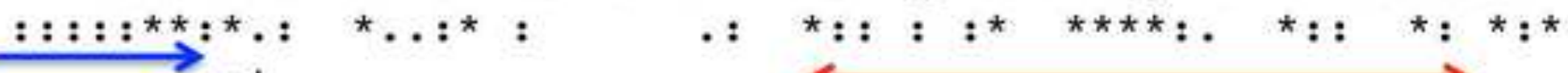
$2 \mathrm{~d}$

GAKGGYQLRVPAEE ISAGDI IRLLEGPITFVES IESEPP---------AQKQLWIRMRDA GAYGGYVLGSEPDAITAGDIIRVLEGPISPVEVLEDEEP-------AKRELWIRIRDA GAQGGYILAREPRDIKVGDIIRVLEGPIAPVECVSQDDPEHCLKFDFCVTKSVWEKVKKS GSQGGYVLSKDPKDIHISNIFDVLEGPIEISDCVESDS---CDNSDYCVTRLLWVKIKES GAQGGYILNRQPEDITVSDIIEVLEGPIEISDCLDGVT---CNNVDCCATRLLWKKIKTS GAQGGYLLSKNAEDITVGDILVVLEGPVALSDCVLDEDV--CENSNMCVTKIVWEKMKKG GPGGGYLLGKNANEIAVGMVISAVDESVDATRCQGRES---CQGGDRCLTHTLWRDLSDR GPGGGYLLGKDASSIAVGEVISAVDESVDATRCQGKGG---CQGGDKCLTHALWRDLSDR *. $*$ * * * . : : : : : $:$ : $:$ :

VRDVLDNTTLKYLAEYVDTSEDLDGYMFYI VKEVLDSTTLEDLASYTDG--EQEAYMFYI IEEVLDSITLADMLKDAEEAQMAQGYMYYI IDNVTKTITLKDMVDDYNSIKNQ IDEVTNSVTLKDIVEDYKAMKEKNEALKIVSRSEENE IEDVIDSITLKDMINDYNKNKLENDITNIKK ITDFLNNITLDELVNNKEVLNVADRQDTDTRRTANGRIQETINVNLRA LTGFLNNITLGELVNNQEVLDVSGRQ--HTHDAPRTRTQDAIDVKLRA ; . .** : . . 
A

B. subtilis

E. coli

T. potens

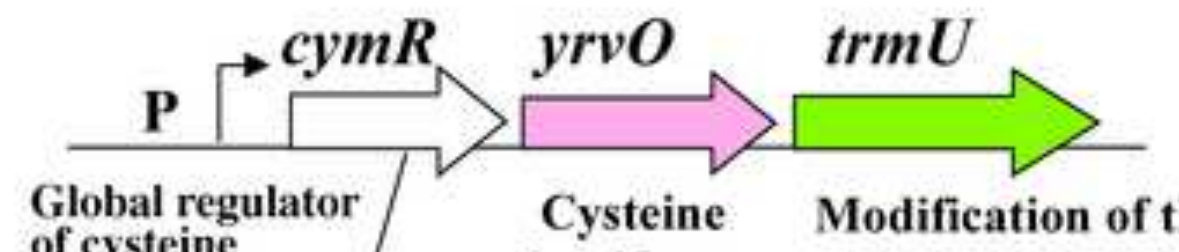

C. perfringens

B

isCR E.C ATAGTTGACCAATTTACTCGGGAT isCR T.P ATAGTTGACCAATTTACTCGGGAAT iSCR C.P ATTGTTGACAAATTTACTCGGTTTT cpe2093 AAAGTTGACAATTTTGATGGGAATT AWWGTTGACMAWWWTRMTSGGNWWT 


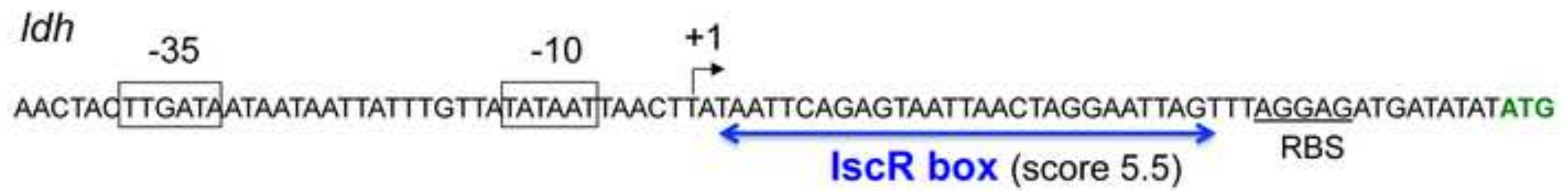

cpe0664

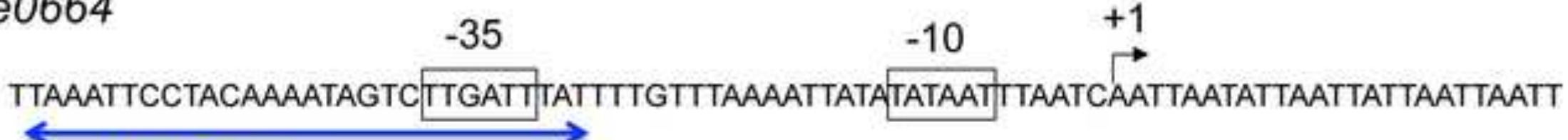

IscR box (score 5.3)

IscR box (score 4.8)

AAAATTAAGTAGGTGATCAAATG

RBS 
Table S1. Oligonucleotides used in this study.

\begin{tabular}{|c|c|c|}
\hline Name & sequence & function \\
\hline \multicolumn{3}{|c|}{ Quantitative RT-PCR } \\
\hline GA99 & TGCAGGATTTGTTGGTTCAA & 5'ldh \\
\hline GA100 & GCACCTTGTGCTAGGTCCAT & 3'ldh \\
\hline GA103 & GGTAGCAATGAGCGATGATG & 5' сре0664 \\
\hline GA104 & TCCGTTCCCACCAAAGTTTA & 3'сре0664 \\
\hline GA105 & CCTGGCTCTTTTGAAGGTGT & 5' cpe1371 \\
\hline GA106 & ACAACCATACCGCATCCATT & 3' cpe1371 \\
\hline GA108 & TCCCAATGTTACCCTTTTTGA & 5' сре2092 \\
\hline GA109 & TTGCAAAGCTCATTTCATGG & 3' cpe2092 \\
\hline GA110 & CTCCTTACAAGGCACCAGGA & 5' сре0818 \\
\hline GA111 & CCCTTTGGCTACTGGAACAC & 3'сре0818 \\
\hline GA112 & ATGCCTGAAACAATGCCTTC & 5' сре0866 \\
\hline GA113 & TTGATCCCAATCCCAGAAAG & 3'cpe0866 \\
\hline GA114 & TGGTACTGCTCCAACTTTCG & 5' cpe1031 \\
\hline GA115 & TTCCACCAACAACTACAGCATC & 3'cpe1031 \\
\hline GA124 & GAGGGAAACATTGGGGTTTT & 5' crt \\
\hline GA125 & ATCAGCACCTGCAACAAATG & 3' crt \\
\hline GA126 & TCAAAAGCAAGCTGAGTGGA & 5' nagL \\
\hline GA127 & CATTGTTGCATGTCCTGTCC & 3' nagL \\
\hline GA30 & TGCCAGAATAGTTGGGGAAG & 5' gyrA \\
\hline GA31 & TACCATGTCCGTCAACAAGC & 3' gyrA \\
\hline \multicolumn{3}{|l|}{ 5'RACE } \\
\hline GA130 & $\begin{array}{l}\text { TTCATAGTCGCTCATTAATGGAT } \\
\end{array}$ & 5'RACE сре0664 \\
\hline GA131 & AGAAGAATCAATAACAAAAGTTAA & 5'RACE cpe0664 int \\
\hline GA132 & TACTAAAAGTATTGAGTTTGGGC & 5'RACE $l d h$ \\
\hline GA133 & GTTATTATAACTATGTCAGAG & 5'RACE ldh int \\
\hline GA51 & TCCTCCTTGAGCACCTCTAA & 5'RACE cpe1786 \\
\hline GA62 & GTCTAGTCGCACAACAA & 5'RACE cpe1786 int \\
\hline \multicolumn{3}{|c|}{ Plasmid constructions } \\
\hline pMTL007-F & $\begin{array}{l}\text { TTAAGGAGGTGTATTTCATATGACCATGATTACG } \\
\end{array}$ & intron variable region \\
\hline pMTL007-R & AGGGTATCCCCAGTTAGTGTTAAGTCTTGG & intron variable region \\
\hline RAM-F & ACGCGTTATATTGATAAAAATAATAATAGTGGG & Erm cassette \\
\hline RAM-R & ACGCGTGCGACTCATAGAATTATTTCCTCCCG & Erm cassette \\
\hline EBSu & CGAAATTAGAAACTTGCGTTCAGTAAAC & intron internal \\
\hline TBD043 & $\begin{array}{l}\text { AAAAAAGCTTATAATTATCCTTAGGATACGATACTGTGCGC } \\
\text { CCAGATAGGGTG }\end{array}$ & IBS cpe1786 \\
\hline TBD044 & $\begin{array}{l}\text { CAGATTGTACAAATGTGGTGATAACAGATAAGTCGATACT } \\
\text { GGTAACTTACCTTTCTTTGT }\end{array}$ & EBS1d cpe1786 \\
\hline TBD045 & $\begin{array}{l}\text { TGAACGCAAGTTTCTAATTTCGATTTATCCTCGATAGAGGA } \\
\text { AAGTGTCT }\end{array}$ & EBS2 cpe1786 \\
\hline IMV484 & GACAAATTTACTCGGTTTTGAT & 5'cpe1786 \\
\hline IMV485 & CTCTATTATTCATTTTCTTCACTC & 3' cpe1786 \\
\hline IMV390 & GGCGAATTCGTAGTATAAAAGCCTACTGG & cpe1786-P-131 EcoRI \\
\hline IMV391 & GGCGAATTCTTATTGTTGACAAATTTACT & cpe1786 P-41 EcoRI \\
\hline IMV394 & GGCGGATCCCTTCCTTTGGTAGATAA & cpe1786 $\mathrm{P}+61 \mathrm{BamHI}$ \\
\hline IMV439 & TTGTTGACAAATTTACGCGGTTTTGATATTATA & T-22G P-cpe1786 \\
\hline IMV440 & TATAATATCAAAACCGCGTAAATTTGTCAACAA & T-22G P-cpe1786 \\
\hline IMV441 & TTGACAAATTTACTCGATTTTGATATTATAATC & G-19A P-cpe1786 \\
\hline IMV442 & GATTATAATATCAAAATCGAGTAAATTTGTCAA & G-19A P-cpe1786 \\
\hline IMV455 & $\begin{array}{l}\text { TTGTTGACAAATTTACGCGATTTTGATATTATAATC } \\
\end{array}$ & \begin{tabular}{|l|l|} 
T-22G/G-19A P-cpe1786 \\
\end{tabular} \\
\hline IMV456 & GATTATAATATCAAAATCGCGTAAATTTGTCAACAA & \begin{tabular}{|l|} 
T-22G G-19A P-cpel786 \\
\end{tabular} \\
\hline EH18 & $\begin{array}{l}\text { AAATCTAGATCACTACTTGTCATCGTCATCCTTGTAGTCGATGTCATGATCT } \\
\text { TTATAATCACCGTCATGGTCTTTGTAGTCTTCATTTTCTTCACTCCTACT }\end{array}$ & $\begin{array}{l}\text { Fusion of a XFlag at the end } \\
\text { of cpel } 786\end{array}$ \\
\hline \multicolumn{3}{|c|}{ 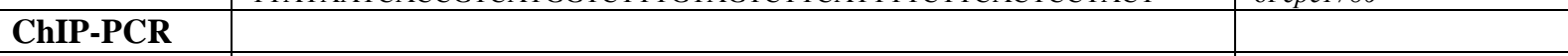 } \\
\hline IMV524 & ACGAAATAAAAATCAAAGTTGACAAT & cpe2093 ChIP-PCR \\
\hline
\end{tabular}




\begin{tabular}{|l|l|l|}
\hline IMV525 & TTGCTACAACCAACTAATACCATCA & cpe2093 ChIP-PCR \\
\hline IMV520 & GAAATTTCCATTTTAAATTCCTACTAAAA & cpe0664 ChIP-PCR \\
\hline IMV521 & AGCATCATCGCTCATTGCTA & cpe0664 ChIP-PCR \\
\hline EH40 & TTGACAAATTTACTCGGTTTTGA & cpe 1786 ChIP-PCR \\
\hline EH41 & ATCAACCATGGCTTTTACAC & cpe1786 ChIP-PCR \\
\hline EH44 & GAGGTGGCTTATGGAAGATAAAA & cpe1031 ChIP-PCR \\
\hline EH45 & CTAGCTATTCCCTTTGCACACA & cpe1031 ChIP-PCR \\
\hline EH50 & GTGTTGGTGCCGCTTTAGG & cpe1371 ChIP-PCR \\
\hline EH51 & GACCTGTAGTTCCAAGTATAAAAACAA & cpe1371 ChIP-PCR \\
\hline
\end{tabular}


Table S2. Genomic identification of candidate IscR-binding sites in Clostridia spp.

\begin{tabular}{|c|c|c|c|c|c|}
\hline Genome & $\begin{array}{l}\text { First gene } \\
\text { locus tag }\end{array}$ & $\begin{array}{l}\text { regulated } \\
\text { operon }\end{array}$ & $\begin{array}{l}\text { Site } \\
\text { Position }\end{array}$ & $\begin{array}{l}\text { Site } \\
\text { Score }\end{array}$ & Candidate IscR-binding site \\
\hline \multirow[t]{6}{*}{ Clostridium perfringens str. 13} & \multirow[t]{2}{*}{ CPE1786 } & \multirow[t]{2}{*}{ iscRSU-trmU } & -80 & 5.8 & TTATTGTTGACAAATTTACTCGGTTTTGA \\
\hline & & & -39 & & ATAAAGTACATCGAATTAGTCAGATTTAG \\
\hline & CPE0103 & Idh & -46 & 5.5 & ATAATTCAGAGTAATTAACTAGGAATTAG \\
\hline & \multirow[t]{2}{*}{ CPE0664 } & \multirow[t]{2}{*}{ hes $B$} & -101 & 5.3 & TAAATTCCTACTAAAATAGTCTTGATTTA \\
\hline & & & -76 & 4.8 & TTTATTTTGTTTAAAATTATATAATTTAA \\
\hline & CPE2093 & yxeONM & -69 & 5.3 & TCAAAGTTGACAATTTTGATGGGAATTAA \\
\hline \multirow[t]{2}{*}{ Clostridium acetobutylicum ATCC 824} & CAC1675 & $i s c R$ & -41 & 5.8 & ACAAAGTAGAGTATTATTGTCGGAATTAA \\
\hline & CAC3288 & SUfCBDSE & -58 & 5.4 & TGAATTCCGACTTAAATGGTCAAGATTAA \\
\hline \multirow[t]{2}{*}{ Clostridium novyi NT } & \multirow{2}{*}{\multicolumn{2}{|c|}{ NT01CX_228. iscRSU-trmU }} & -82 & 5.9 & TTAATGTTGACAAAAACACTCGGATTTGA \\
\hline & & & -41 & 5.6 & AGAATTCATAGTATAACACTCGGATTTAA \\
\hline \multirow[t]{2}{*}{ Clostridium kluyveri DSM 555} & CKL_1317 & iscRSU & -71 & 5.8 & TTATTGTTGACAAGTTTACTCTGATTTGA \\
\hline & CKL_0828 & sUfCBDSE & -41 & 5.1 & TTAAATATGAGTCAAATACTCGGATTTAA \\
\hline Clostridium butyricum 5521 & CBY_2622 & iscRSU-trmU & -61 & 5.3 & CAATAGCCGAGTATTTTGATAAGATATAA \\
\hline \multirow[t]{2}{*}{ Clostridium beijerincki NCIMB 8052} & Cbei_1097 & iscRSU-trmU & -105 & 5.7 & CAAAAGCCGAGTATTTTGGTAAGATATAA \\
\hline & Cbei_4356 & cysk & -55 & 5.2 & TTATAACATAGTAAACTGATAAGAATTAT \\
\hline \multirow[t]{2}{*}{ Clostridium tetani E88 } & СТC01049 & iscRSU-trmU & -92 & 5.2 & TTATAGTTGACAGGAATACTCGGATTTGT \\
\hline & & & -52 & 5.5 & TGAAAGTTTAGTAAAGCAGTAGACTTTCA \\
\hline \multirow{2}{*}{\multicolumn{2}{|c|}{ Clostridium botulinum A str. ATCC 35 СВО2569 }} & iscRSU & -82 & 4.8 & ATATTGTTGACAGGTTTAGTCTGATTTGC \\
\hline & & & -43 & & ATAAATCATAGTAAAGTGGTCAACATTAA \\
\hline \multirow[t]{3}{*}{ Clostridium bartlettii DSM 16795} & \multirow{3}{*}{\multicolumn{2}{|c|}{ CLOBAR_021 iscRSU-trmU }} & -113 & 6.6 & TTAATTCTGACTAAAATAGTCAAAATTAA \\
\hline & & & -88 & 5.7 & TTAATGTTGACAAAAACACTCAAGTATAA \\
\hline & & & -41 & 4.7 & AGAAATCCTACTAAAAAAGTAGGAATAAG \\
\hline \multirow[t]{3}{*}{ Clostridium hiranonis DSM 13275} & \multirow{3}{*}{\multicolumn{2}{|c|}{ CLOHIR_011s iscRSU-trmU }} & -103 & 5.9 & $\overline{\text { ACAAATCATACTAAAATAGTAGGAAATAA }}$ \\
\hline & & & -77 & 5.7 & TAATACTTGACAAAAATAGTCGGATATAA \\
\hline & & & -43 & & TTAAACCATAGTAAAACAGTAGGAATTAA \\
\hline \multirow[t]{2}{*}{ Clostridium difficil e 630} & \multirow[t]{2}{*}{ CD1278 } & \multirow[t]{2}{*}{ iscRSU-trmU } & -98 & & TTAATCTTGACAAAATTAGTAGGGTATAA \\
\hline & & & -53 & 5.4 & GTAATTCCTACTAAAACAGTATGAATTAG \\
\hline \multirow[t]{2}{*}{ Clostridium sp. OhILAs } & Clos_1671 & iscRSU & 1 & 5.2 & TGAATGTTGACAAAAATAGTAGGGTATAC \\
\hline & Clos_0333 & cysk & -43 & & ATAAAACCTATCGGTTTACTATGAATTAA \\
\hline \multirow[t]{2}{*}{ Clostridium cellulolyticum $\mathrm{H} 10$} & Ccel_1933 & iscRSU-trmU & -93 & 6.1 & TTAAATCATAGTAATTTAATTGGAATTAA \\
\hline & Ccel_3186 & cysK & -106 & 5.2 & TTAATTCATACTAATTAGATAGGAAATAT \\
\hline Clostridium nexile DSM 1787 & \multicolumn{2}{|c|}{ CLONEX_030 iscRSU-trmU } & -51 & 5.9 & ATAAACCCTAGTAATTCACTAGGAATTAA \\
\hline Clostridium scindens ATCC 35704 & \multicolumn{2}{|c|}{ CLOSCI_0139 iscRSU-trmU } & 18 & 5.7 & AGAAATCCTAGCAAATTGCTAGGAATTAA \\
\hline Clostridium sp. SS2/1 & \multicolumn{2}{|c|}{ CLOSS21_00( iscRSU-trmU } & -38 & 5.4 & TGAAATCCGAGTTATATAGTCGGGATTGA \\
\hline \multirow[t]{2}{*}{ Thermincola potens JR } & \multirow{2}{*}{\multicolumn{2}{|c|}{ TherJR_1914 iscRSU-trmU }} & -120 & 5.2 & AAAAATCTTAGTATTTTAGTTGGAATTTT \\
\hline & & & -50 & 4.8 & CCATAACCGAGTGCAACACTAGGAATTAA \\
\hline
\end{tabular}

